\section{Entrepreneurial learning from failure. A systematic review}

\section{Entrepreneurial learning from failure}

\author{
Wolfgang Lattacher and Malgorzata Anna Wdowiak \\ Faculty of Management and Economics, \\ Department of Innovation Management and Entrepreneurship, \\ University of Klagenfurt, Klagenfurt, Austria
}

\begin{abstract}
Purpose - Failure plays a pivotal role in entrepreneurial learning. Knowledge of the learning process that enables an entrepreneur to re-emerge stronger after a failure, though considerable, is fragmented. This paper systematically collects relevant literature, assigns it to the stages of the experiential learning process (concrete experience, reflective observation, abstract conceptualization, active experimentation; Kolb, 1984), evaluates the research coverage of each stage and identifies promising avenues for future research.

Design/methodology/approach - This systematic literature review follows the guidelines articulated by Short (2009) and Tranfield et al. (2003), using Web of Science and EBSCO as primary data sources. Kolb's (1984) experiential learning theory provides a basis for organizing the identified material into a framework of entrepreneurial learning from failure.

Findings - The literature provides insights on all stages of the process of entrepreneurial learning from failure. Particularly well elaborated are the nature of failure and its triggering effect for reflection, the factors influencing reflection, the contents of the resulting learning and their application in entrepreneurial reemergence. Other topics remain under-researched, including alternative modes of recovery, the impact of personal attributes upon reflection, the cognitive processes underlying reflection, the transformation of failurebased observations into logically sound concepts and the application of this learning in non-entrepreneurial contexts.

Originality/value - This review provides the most complete overview of research into the process of entrepreneurial learning from failure. The systematic, theory-based mapping of this literature takes stock of current knowledge and proposes areas for future research.
\end{abstract}

Keywords Entrepreneurial failure, Entrepreneurial learning, Experiential learning, Re-emergence,

Sensemaking

Paper type Literature review

\section{Introduction}

"Entrepreneurship is a process of learning" (Minniti and Bygrave, 2001). Entrepreneurs can profit from particularly rich learning in the aftermath of critical events (Cope, 2011). One of the most critical events an entrepreneur can face is failure (Espinoza-Benavides and Díaz, 2019) - the closure of a business that does not meet a minimum threshold for economic viability (Cope, 2011; Ucbasaran et al., 2013). Given the considerable degree of uncertainty and ambiguity associated with entrepreneurship, failure is a common phenomenon (Politis, 2008; Sarasvathy, 2001). Entrepreneurial learning from failure is therefore important for practitioners and a topic that has recently gained traction in research.

In practice, entrepreneurial learning is important, as it improves the individual's stock of knowledge. The knowledge acquired through failure can, under certain conditions, facilitate successful entrepreneurial re-emergence. Moreover, failed entrepreneurs may profit from

(C) Wolfgang Lattacher and Malgorzata Anna Wdowiak. Published by Emerald Publishing Limited. This article is published under the Creative Commons Attribution (CC BY 4.0) licence. Anyone may reproduce, distribute, translate and create derivative works of this article (for both commercial and non-commercial purposes), subject to full attribution to the original publication and authors. The full terms of this licence may be seen at http://creativecommons.org/licences/by/4.0/legalcode.

Financial support from the Oesterreichische Nationalbank (Austrian Central Bank, Anniversary Fund, project number: 16571) is gratefully acknowledged.

1093

Received 13 February 2019 Revised 21 September 2019 20 February 2020 2 April 2020 Accepted 4 April 2020

$$
\text { (n) }
$$


IJEBR

26,5

1094

learning outcomes in other occupational contexts and when coping with subsequent critical events. From a research perspective, entrepreneurial learning from failure is interesting for at least three reasons. First, failure, despite having gained considerable research interest recently, still constitutes an emerging field with a number of questions to be answered (McGrath, 1999; Ucbasaran et al., 2013). Second, the application of learning theories to the context of failure may not only improve our understanding of failure but also yield opportunities to further advance learning theory. Third, research into how entrepreneurs learn from failure responds to the call for more research that facilitates a dynamic view of entrepreneurship (Cope, 2005).

Research on entrepreneurial learning from failure emerged more than fifteen years ago (Shepherd, 2003), gaining momentum in the last few years (more than half of all studies on the topic have appeared in 2015 or later). As initially noted by Shepherd (2003), research provides rich evidence that failure yields opportunities for learning but at the same time represents a difficult context in which to learn. While some interesting insights about the learning mechanism can be found in qualitative overview studies (Amankwah-Amoah et al., 2018; Cope, 2011; Frota Vasconcellos Dias and Martens, 2019), most research is situated in highly specialized sub-fields and discusses the influence of particular single factors on learning from failure. These factors include the individual's initial stock of knowledge (Huovinen and Tihula, 2008; Politis, 2005; Politis and Gabrielsson, 2009), personality traits such as narcissism (Liu et al., 2019), the attribution of the failure to particular causes (Eggers and Song, 2015; Walsh and Cunningham, 2017; Yamakawa et al., 2015) and emotions (Dias and Teixeira, 2017; Shepherd, 2003; Shepherd et al., 2009). As learning is not complete until the resulting knowledge is applied to a new (entrepreneurial) context (Yamakawa and Cardon, 2015), scholars also address factors influencing knowledge transfer. Findings suggest that mindfulness of knowledge transfer (Rerup, 2005) as well as the proximity between the two ventures in time and industry (Eggers and Song, 2015) influence learning effectiveness.

Existing research thus provides deep insights into many of the elements that shape the process of entrepreneurial learning from failure. However, the high degree of specialization of many of these research endeavors leads to a fragmentation of the field (Nogueira, 2019). This, in turn, limits the progress of research, as scholars struggle to build appropriately on the work of others and to identify clear directions for future endeavors. We acknowledge the valuable review works that have been conducted by Ucbasaran et al. (2013) and Wang and Chugh (2014). However, these studies address entrepreneurial learning from failure as merely one facet of a broader research context (Ucbasaran et al., 2013: entrepreneurial failure; Wang and Chugh, 2014: entrepreneurial learning). Further, at the time of their publication, less than half of the current literature in the field existed. As a consequence, the fragmentation of the literature on entrepreneurial learning from failure requires fresh consideration, and additional review work is necessary for the further development of the field.

The present paper is aimed at addressing these issues. Systematic review methodology is applied to collect and critically evaluate existing literature (Short, 2009; Tranfield et al., 2003) using the databases EBSCO and Web of Science. The final sample of 40 articles is organized and discussed from a processual perspective that is informed by Kolb's (1984) theory of experiential learning. Kolb (1984) identifies four stages that an individual must go through in order to learn effectively from an experience: concrete experience, reflective observation, abstract conceptualization and active experimentation. In this review, literature findings are classified according to these stages to generate a theory-guided, processual overview of the field. Through a comparison of what should be covered in each stage according to experiential learning theory (Kolb, 1984) and what is actually discussed in the existing literature, avenues for future research are derived. Our results reveal that the existing research - while in different intensities and a dispersed manner - thematizes all stages of the experiential learning process (Kolb, 1984). Particularly well elaborated are the nature of 
failure and its triggering effect for reflection, specific factors influencing reflection (emotion and attribution), the contents of the resulting learning (e.g. person-, venture- or relationshiporiented) and their application in entrepreneurial re-emergence. Under-researched are alternative recovery modes (e.g. epiphanies), personal characteristics (e.g. resilience and narcissism) and their impact upon reflection. Further, the cognitive processes underlying reflection itself and especially the transformation of failure-based observations into logically sound concepts have not adequately been covered so far. Likewise, little attention has been paid to the application of learning in non-entrepreneurial contexts. With these insights, the present review contributes to research on entrepreneurial learning from failure in at least two ways. First, it provides what is, to our knowledge, the most comprehensive overview of the process of entrepreneurial learning from failure-one that, moreover, results from a systematic literature search and is informed by a clear theoretical background. Second, it identifies promising avenues for further research to build a foundation for future research endeavors.

The paper is structured as follows. First, the theoretical background and conceptual understanding of entrepreneurial learning and failure are given. Second, the methodology, in particular the systematic review approach, is presented. Third, the findings from the literature, which are processual in their focus and guided by theory, are provided. Fourth, the status quo of the research field is critically discussed. Based on this discussion, fruitful areas for future research are proposed and the practical implications of the study, as well as its limitations, are considered.

\section{Theoretical and conceptual basis}

\subsection{Entrepreneurial learning}

Entrepreneurial learning is a promising research field at the interface of entrepreneurship and individual as well as organizational learning (Harrison and Leitch, 2005; Kim, 1993). Often defined as "learning in the entrepreneurial process" (Holcomb et al., 2009; Politis, 2005; Ravasi and Turati, 2005; Wang and Chugh, 2014), the field is particularly concerned with how and when learning takes place (Wang and Chugh, 2014). As Wang and Chugh (2014) show, studies on entrepreneurial learning have utilized a wide range of theoretical perspectives: experiential learning, organizational learning, social cognitive theory, population ecology and configuration theory. Among these theoretical perspectives, experiential learning has emerged in recent years as the most influential theory in entrepreneurial learning research (Fust et al., 2018).

The perspective of experiential learning conceptualizes entrepreneurial learning as a process of updating a subjective stock of knowledge based on experiences (Cope, 2005; Minniti and Bygrave, 2001; Politis, 2005). The entrepreneur learns from a given experience via personal reflection and direct action (Politis and Gabrielsson, 2009). The nature of the experience significantly influences the learning process and its outcomes. As Cope and Watts (2000) find, insignificant experiences provoke only "lower-level" learning, which involves incremental, adaptive changes to existing mental models. Experiences that are perceived as critical or discontinuous, however, bear the potential to occasion "higher-level" learning (Cope, 2003). This process involves considerable reflection and may ultimately lead to significant changes in mind and behavior (Cope, 2003; Pittaway and Thorpe, 2012). As the present paper is concerned with failure - a very critical event in the life of an entrepreneur (Espinoza-Benavides and Díaz, 2019) — the concrete process of "higher-level" learning and its influencing factors are of particular interest. In order to structure existing research findings related to this process, we utilize the experiential learning framework developed by Kolb (1984).

Kolb's approach to experiential learning theory not only is widely recognized in psychology but also serves as the dominant theoretical framework used in entrepreneurship 
IJEBR

26,5

1096

research for understanding how entrepreneurs learn (Morris et al., 2012). Kolb perceives learning as "the process whereby knowledge is created through the transformation of experience" (Kolb, 1984). Drawing on the work of Lewin (1951) and others (e.g. Dewey, 1910; Piaget, 1971), Kolb defines four stages a learner must pass through to learn effectively from an experience. First, the individual is exposed to a concrete experience, which is subsequently analyzed through reflective observation. The resulting insights are then shaped into new knowledge via abstract conceptualization and tested via active experimentation (see Figure 1).

The concrete experience is the starting point and basis for learning. It acts as a reference line for testing the existing abstract concepts. Kolb, citing Hegel (1953), recognizes the importance of a certain degree of significance the experience has for the learner. In fact, "any experience that does not violate expectation is not worthy of the name experience" (Hegel, 1953). Similarly, Dewey (1933), whose work is influential for Kolb's, stresses that in order to initiate reflection and learning, the daily flow must be interrupted by a "deep" experiencefor example, being stuck with a problem, something unusual or strange. In addition to the concrete experience itself, the learner's initial reaction is a formative element of Kolb's first learning stage. This reaction comprises a preliminary evaluation and comparison of the event with existing abstract concepts. In the second stage, a deeper type of analysis, namely reflective observation, takes place. This reflection has to be performed deliberately and includes a variety of perspectives. As Duley (1981) stresses, the difficulty of executing this kind of reflection tends to be the greatest obstacle to individual learning. With a deeper sense of what has happened, the learner subsequently enters the stage of abstract conceptualization. In this stage, creativity is more important than reflectivity. The learner has to play, mentally, in order to integrate observations into logically sound theories. As a final step, the learner enters the stage of active experimentation. Applying the abstract knowledge he or she has generated, the individual tests its adequacy. If another unexpected experience results from this experimentation, a new learning episode starts. As a consequence, over the whole entrepreneurial life, the process illustrated in Figure 1 is cyclical rather than sequential (Kolb and Kolb, 2018). Yet for the purpose of analyzing a specific event, the reduction to a four-step process appears adequate (Politis, 2005).

\subsection{Entrepreneurial failure}

Entrepreneurial failure has emerged as an important field of research, since the seminal work of McGrath (1999) raised scholars' awareness of the fact that failure is an inherent part of the entrepreneurship phenomenon. Although the body of knowledge on this subject has grown tremendously since then, there are still many ambiguities regarding our understanding of entrepreneurial failure (He et al., 2018; Jenkins and McKelvie, 2016; Wennberg and DeTienne, 2014). In a very broad sense, failure includes every negative deviation of actual outcomes from expected ones (Politis and Gabrielsson, 2009). If we try to grasp the basic concept of entrepreneurial failure, three levels of interpretation become apparent: firstly, failure as the disappearance of the firm from a market, secondly failure in an organizational term and thirdly failure as defined by the personal perception of the entrepreneur.

Within the first vein of interpretation, market persistence is regarded as a core criterion for entrepreneurial failure (Mitchell and Singh, 1993; Perkins, 2014). This seems to be quite a narrow interpretation of the concept of failure, one closely related to ecological approaches (Fotopoulos and Louri, 2000). However, the non-survival of the company within a given market does not necessarily mean the cessation of the business, as an organization may

Figure 1.

Entrepreneurial learning process (cf. Kolb, 1984)
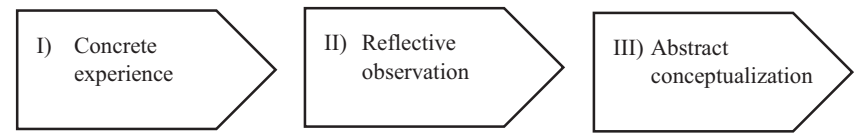

IV) Active experimentation 
continue to exist, offering new products or services and competing in new markets or new economies (Josefy et al., 2017).

The second lens focuses on organizational failure, which is the discontinuance of a business (Bruno et al., 1992; He et al., 2018; Singh et al., 2015). This dimension primarily describes cases of bankruptcy and insolvency (Shepherd, 2003), and it also encompasses cases in which businesses have not yet reached insolvency but nevertheless suffer financial losses and poor economic viability (Ucbasaran et al., 2013). However, companies can close for reasons of a more neutral or even positive nature. Closure can occur due to the retirement of the entrepreneur or to personal changes (the desire to work socially or in another profession) (Wennberg and DeTienne, 2014; Wennberg et al., 2010). It can also happen because of serious health problems or for reasons relating to family (DeTienne and Wennberg, 2016), as well as due to unexpected circumstances such as legal constraints, war or pandemic (e.g. Wdowiak et al., 2017).

Finally, the individual lens focuses on failure defined by the fact that it is (cognitively) perceived as such by the entrepreneur, regardless of whether or not the company survives (Cope, 2011; Ucbasaran et al., 2013). A rather obvious case refers to the closure of the company, which also involves a personally perceived failure of the entrepreneur (Cope, 2011; Singh et al., 2007). In some cases, however, the company does survive, but its development is not satisfactory from the entrepreneur's point of view, which leads to his or her withdrawal from the company (Ucbasaran et al., 2010). Researchers argue that well-educated and experienced entrepreneurs, in particular, are willing to take this last step because they have especially high growth expectations or because they have better opportunities on the labor market (Gimeno et al., 1997).

This plethora of understandings of entrepreneurial failure, coupled with the wide range of research questions addressed in existing research (Jenkins and McKelvie, 2016), obviously leads to methodological variation. Differences become particularly apparent in the approach to measuring entrepreneurial failure. On one side, failure is measured objectively. Most often, economic performance is used as the basis for measurement in objective approaches, as poor financial figures are generally the basis for cases of bankruptcy and insolvency (see, e.g. Jenkins and McKelvie, 2016; Shepherd, 2003; Shepherd et al., 2009; Yamakawa et al., 2015). On other side, failure is measured subjectively. Subjective approaches build on the comparison of individually set goals and actual outcomes (Jenkins and McKelvie, 2016). Here, failure can be ascribed even to well-functioning companies that do not meet the individually defined criteria (see, e.g. He et al., 2018; Sitkin, 1992). Another subjective way of measuring failure takes into account the personal attitude and situation of the entrepreneur, acknowledging that entrepreneurs differ in how deeply failure impacts them psychologically and financially (Cope, 2011).

In defining entrepreneurial failure for our own research purpose, we rely upon the organizational lens (discontinuance of business) and objective criteria of failure (economic performance). This approach leads to a relatively homogenous sample of organizations in terms of financial performance and triggering events. Consequently, it allows for comparison of subsequent individual reactions. Many studies that focus on learning from failure adopt this perspective (e.g. Byrne and Shepherd, 2015; Cope, 2011; Shepherd, 2003; Stam et al., 2008), which facilitates the comparison of findings. We follow Ucbasaran et al. (2013) in going beyond the very narrow criterion of bankruptcy. In fact, we include cases in which businesses are closed because they consistently create losses. As a consequence, our working definition of failure for this literature review is the closure of a business because it has not met a minimum threshold for economic viability.

\section{Methodology}

We conducted a systematic literature review (SLR) following the guidelines of Short (2009) and Tranfield et al. (2003), which are established in the area of entrepreneurship (Bird et al., 
IJEBR

26,5

\section{8}

2012; Nason et al., 2015; Ucbasaran et al., 2013). The SLR process is illustrated in Figure 2 (see Wang and Chugh, 2014 for a similar approach). As a starting point, we defined our research objectives, which can be summarized as analyzing the status quo and providing avenues for future research in the field of entrepreneurial learning from failure. Second, we defined our research boundaries according to the definitional considerations presented above. We focus on entrepreneurial learning from failure and define failure as the closure of a business because it has not met a minimum threshold for economic viability (Cope, 2011; Ucbasaran et al., 2013). Based on these objectives and this definition, we set the following inclusion criteria. We searched for peer-reviewed articles in the electronic databases EBSCO and Web of Science. Within these databases, we searched simultaneously in title, keywords and abstract fields. As learning from failure is a topic in various contexts, theoretical backgrounds and research domains, we opted for a broad approach in defining the search terms. We were aware that this would imply a high number of articles to be excluded manually. However, the rather small field of our research allows for such a procedure, which decreases the risk (immanent in SLR)

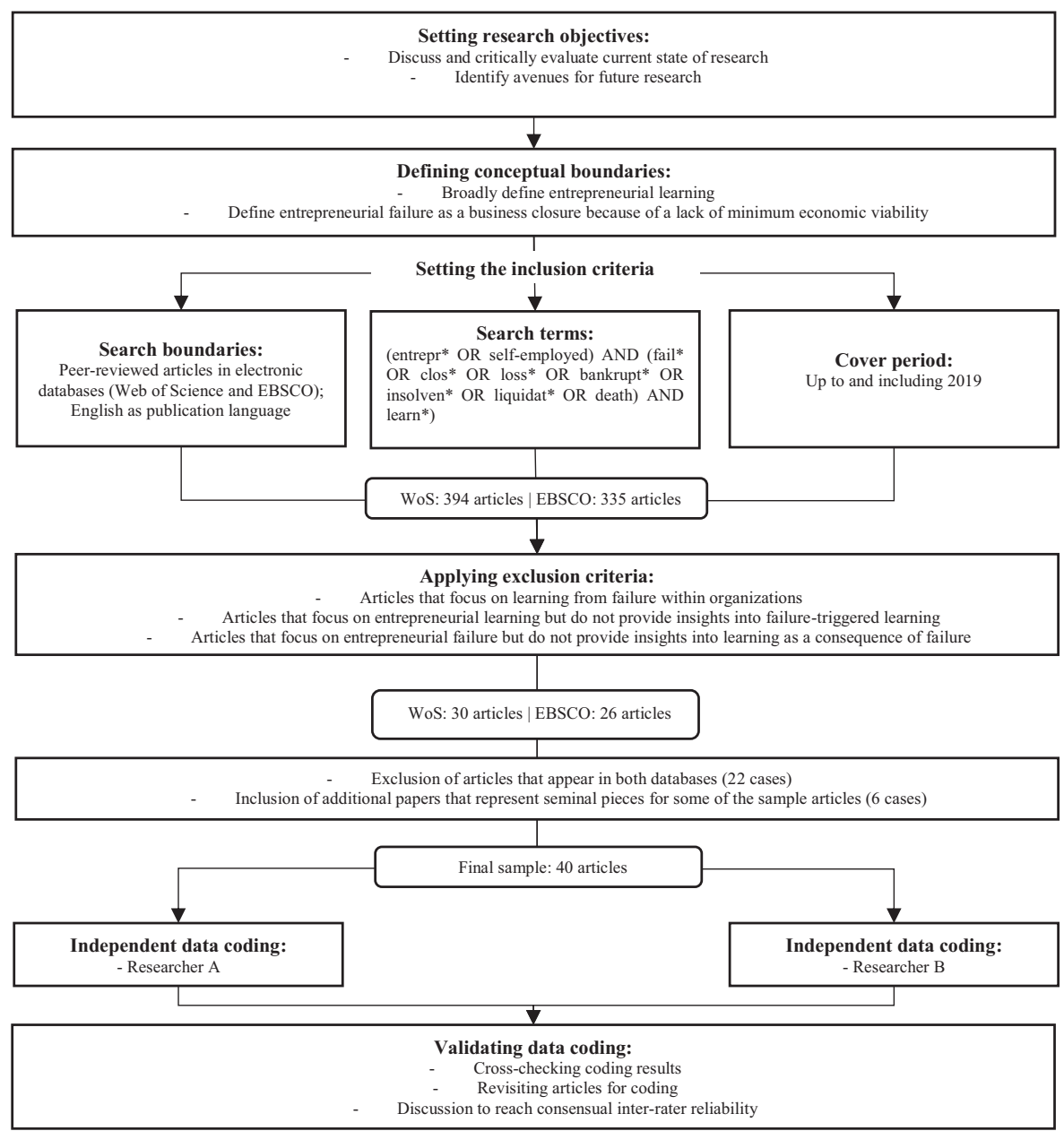

Figure 2.

Systematic literature review approach 
of missing relevant publications (Pittaway et al., 2004). Our search operators were: (entrepr* OR self-employed) AND (fail* OR clos* OR loss* OR bankrupt* OR insolven* OR liquidat* OR death) AND learn*). Applying this search agenda and limiting the search to publications in the English language led to 394 results in Web of Science and 335 results in EBSCO. As we aimed to provide a full picture of the development of research in this area over time, we decided to refrain from setting time restrictions. Thus, all relevant publication activity up to and including 2019 is considered. To ensure a systematic and reliable approach, we defined exclusion criteria (for details see Appendix, Table A1). The most frequent reasons for exclusion were that articles 1) lacked an entrepreneurial focus (i.e. were situated in an organizational learning context), 2) did not focus on failure-based learning (i.e. referred to learning in other contexts than failure), and 3) provided insights into the phenomenon of entrepreneurial failure without a considerable contribution on learning (i.e. targeted failurerelated questions that are irrelevant from a learning perspective). Both researchers separately read all titles and abstracts to exclude irrelevant articles. Cases of doubt were discussed and consensus was reached. For further validation, a third researcher independently applied the exclusion criteria to 100 articles gathered from Web of Science. In 99 cases, exclusion outcomes mirrored ours. In the remaining case, a consensus was reached. Applying the exclusion criteria, 30 articles from Web of Science and 26 from EBSCO were found to be relevant. After the elimination of duplicates (22), we carefully read the remaining papers. In the course of this process, six additional articles came to our attention which focused on topics linked to learning. As they delivered important additional insights, we decided to include them in the review. Consequently, our final sample for the review consists of 40 articles.

To prepare the relevant information for the literature analysis, all sample articles were read again and open coding was applied. Specifically, we identified which of the four stages of experiential learning each publication considered. In addition, we analyzed the articles' key contributions and collected general information relating to authorship, methodology and publication outlet. To secure an objective process, the coding of all articles was executed by both researchers separately. Although there was a degree of subjective judgment involved in the classification of the literature results according to the experiential learning phases, the coding of 36 of 40 sample articles was consistent. In the remaining four cases, a consensus was reached by revisiting the articles and discussing the nature of their findings. As a consequence, the final data basis for this review represents the shared understanding of the two researchers.

\section{Results}

\subsection{Development of the field}

Entrepreneurial learning from failure is a young and highly specialized research stream, informed by the literatures on entrepreneurial learning and entrepreneurial failure. As illustrated in Figure 3, the first research on this topic emerged at the beginning of the twentyfirst century. While relevant publications remained rare until 2010, research interest in this field increased considerably in subsequent years. Indeed, more than half of all relevant articles were published in 2015 or later. While the still limited number of studies and the heterogeneity of their research purposes make it difficult to generalize about the emergence of the field, we attempt to elaborate some major themes that have shaped the field so far.

Influenced by the call issued by McGrath (1999) to correct the bias in entrepreneurship research toward success, scholars began to shed light on failure-related topics. This wave first hit the entrepreneurial learning literature at the beginning of the twenty-first century, when Shepherd (2003) reflected on the learning process following business failure and the role of grief as an important influencing factor [1]. Additional studies of the learning process were published two years later, when Politis (2005) and Rerup (2005), both aiming for a general
Entrepreneurial learning from failure

1099 


\section{IJEBR 26,5}

1100

Figure 3.

Publication distribution (time and methodology)
8

7

6

5

4

3

2

1

0

20032004200520062007200820092010201120122013201420152016201720182019

understanding of entrepreneurial learning from experience, specifically elaborated on failure as an important type of experience. From 2007 onward, empirical studies on a wide range of relevant topics, such as re-engagement (Stam et al., 2008), experience transformation (Huovinen and Tihula, 2008), grief (Shepherd et al., 2009), attitudes toward failure (Politis and Gabrielsson, 2009), comparative optimism (Ucbasaran et al., 2010) and attribution (Ucbasaran et al., 2011) emerged. These studies increased knowledge but also led to fragmentation, which was partly solved by a second wave of conceptual studies (2012-2014) that sought to make sense of the earlier empirical findings (Coad, 2014; Pittaway and Thorpe, 2012; Ucbasaran et al., 2013). The substantial body of recent research shows three main foci. First, studies have tested the (learning-based) link between failure and performance increase in subsequent entrepreneurial endeavors (Boso et al., 2019; Paik, 2014; Parker, 2013). Second, research has attempted to provide a holistic view of the learning process from failure to re-emergence (Amankwah-Amoah et al., 2018; Dias and Teixeira, 2017; Frota Vasconcellos Dias and Martens, 2019), applying qualitative methodology. Third, scholars, drawing on learning from failure, have focused on changes in specific behaviors-such as internationalization (Lafuente et al., 2019), strategic action (Lin et al., 2019) and negotiation of venture capital (Nahata, 2019) — upon entrepreneurial re-emergence.

\subsection{Provenance of the research}

Consistent with our selection criteria, all articles were published in peer-reviewed journals. Most papers were found in the Journal of Business Venturing (seven) and Entrepreneurship Theory and Practice (five), as well as the International Journal of Entrepreneurial Behavior and Research (four). As far as the country of author's affiliation is concerned, the United States of America (23) and the United Kingdom (21) were the most important research spots. On a continental level, most scholars were affiliated with universities in Europe (43), followed by North America (25). The remaining continents provided lower numbers of relevant contributions (Asia: ten; Australia/Oceania: nine; Africa: four; South America: four).

Looking at research collaborations (indicated by differing affiliations among co-authors), one can see that 14 papers were crafted in international collaborations, with 12 of them 
originating from two or more continents. In all 12 intercontinental collaborations, at least one scholar had an affiliation in the United States. While earlier papers emerged primarily through collaborations between the United States and Europe, more recent collaborations have included researchers from Africa and Asia. In general, a rising trend toward cooperation is visible, as about two-thirds of all collaborative publications stem from the last four years.

\subsection{Methods}

Research on entrepreneurial learning from failure utilizes conceptual, qualitative and quantitative approaches. Among the 40 studies in our sample, eight apply a purely conceptual lens, 14 use qualitative methods, 16 quantitative methods and two a mixedmethod approach. A temporal perspective reveals that early research predominantly applied conceptual lenses to create a basic understanding of the phenomenon of learning from failure (Politis, 2005; Rerup, 2005; Shepherd, 2003). Recent research, by contrast, is often of an empirical nature, utilizing qualitative and quantitative approaches with nearly similar frequency.

Qualitative studies use samples of one (Huovinen and Tihula, 2008; Pretorius and le Roux, 2011) to (initially) 30 (Walsh and Cunningham, 2017) "failed" entrepreneurs. Thirteen of the 14 qualitative studies build on in-depth interviews. In some cases (e.g. Byrne and Shepherd, 2015), the data basis is expanded by observation and written documents. To approach the challenge of biases stemming from the processual nature of learning, studies either utilize narrative interview techniques that help participants to recall relevant information (e.g. Corner et al., 2017) or include informal follow-up conversations (Singh et al., 2015). Quantitative studies are based on samples of between 142 (He et al., 2018) and 41,259 (Nielsen and Sarasvathy, 2016) entrepreneurs. Several works compare the performance of initial and subsequent entrepreneurial attempts on the basis of income- or profit-related data (see, e.g. Chen, 2013; Parker, 2013). Additional descriptive statistics on the research methods are presented in Table 1. For an overview of sample sizes by methodology, see Appendix Table A2.

\subsection{Key contributions}

Existing research on entrepreneurial learning from failure predominantly addresses three issues. One group of papers explores the question of whether learning from failure, as such, exists and to what extent it positively influences future venture endeavors. This area of inquiry is informed mainly by a conceptual paper by Coad (2014) and a number of quantitative studies dedicated to testing the failure-learning and/or failure-future performance relationship (Boso et al., 2019; Espinoza-Benavides and Díaz, 2019; Mueller and Shepherd, 2016; Paik, 2014; Parker, 2013). While Coad (2014) in his conceptual work is critical about the effects of failure-induced learning, empirical findings predominantly suggest that, under certain circumstances, learning from failure is possible. A second group of articles focuses on factors that are assumed to influence learning (for an overview see Wei et al., 2019). Among those factors, emotion (Byrne and Shepherd, 2015; Corner et al., 2017; Shepherd, 2003; Shepherd et al., 2009) and failure attribution (Cardon et al., 2011; Eggers and Song, 2015; Mantere et al., 2013; Ucbasaran et al., 2011; Walsh and Cunningham, 2017; Yamakawa and Cardon, 2015; Yamakawa et al., 2015) are most frequently studied. Further factors of interest are mindfulness (Rerup, 2005), attitude toward failure (Politis and Gabrielsson, 2009), comparative optimism (Ucbasaran et al., 2010), stigma (Singh et al., 2015), pre-education (Nielsen and Sarasvathy, 2016), failure velocity (He et al., 2018) and narcissism (Liu et al., 2019). A third group of papers takes a broader view by exploring the learning process or parts thereof. Areas of inquiry include the transformation of experience into knowledge (Huovinen and Tihula, 2008); failure perception, reflection and the resulting 
IJEBR

26,5

1102
Table 1.

Literature for review

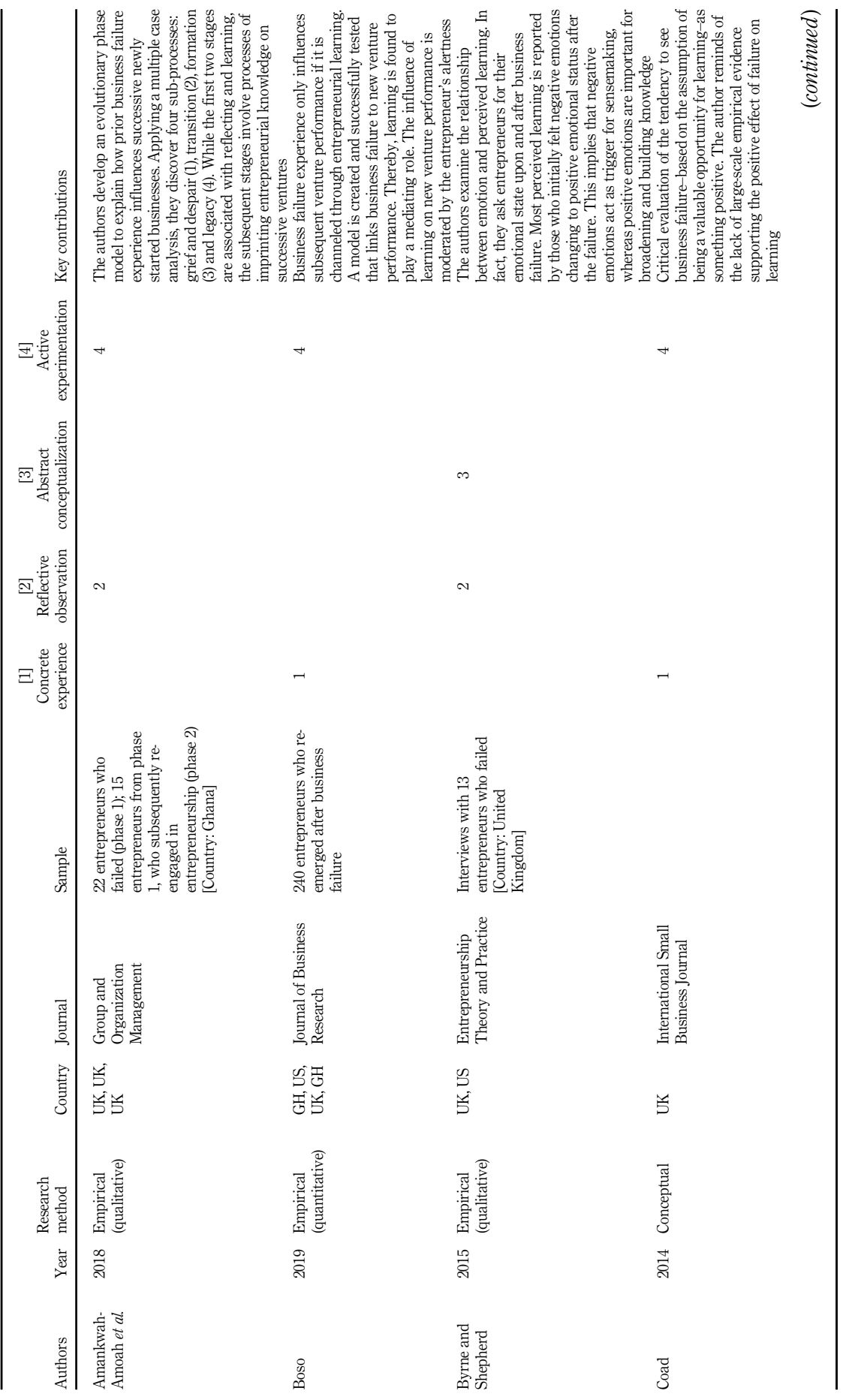




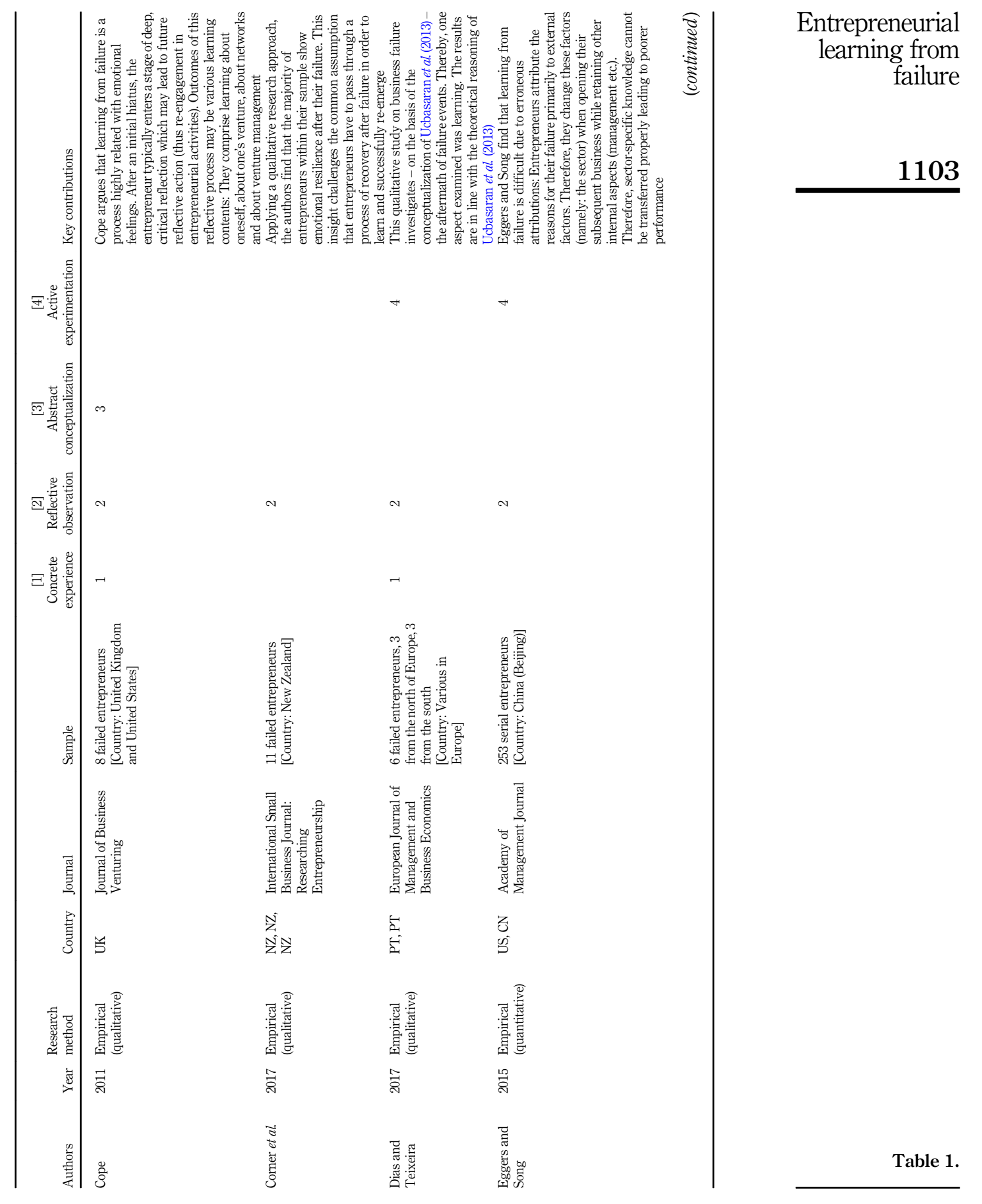




\begin{tabular}{l} 
IJEBR \\
26,5 \\
$\mathbf{1 1 0 4}$ \\
\hline
\end{tabular}

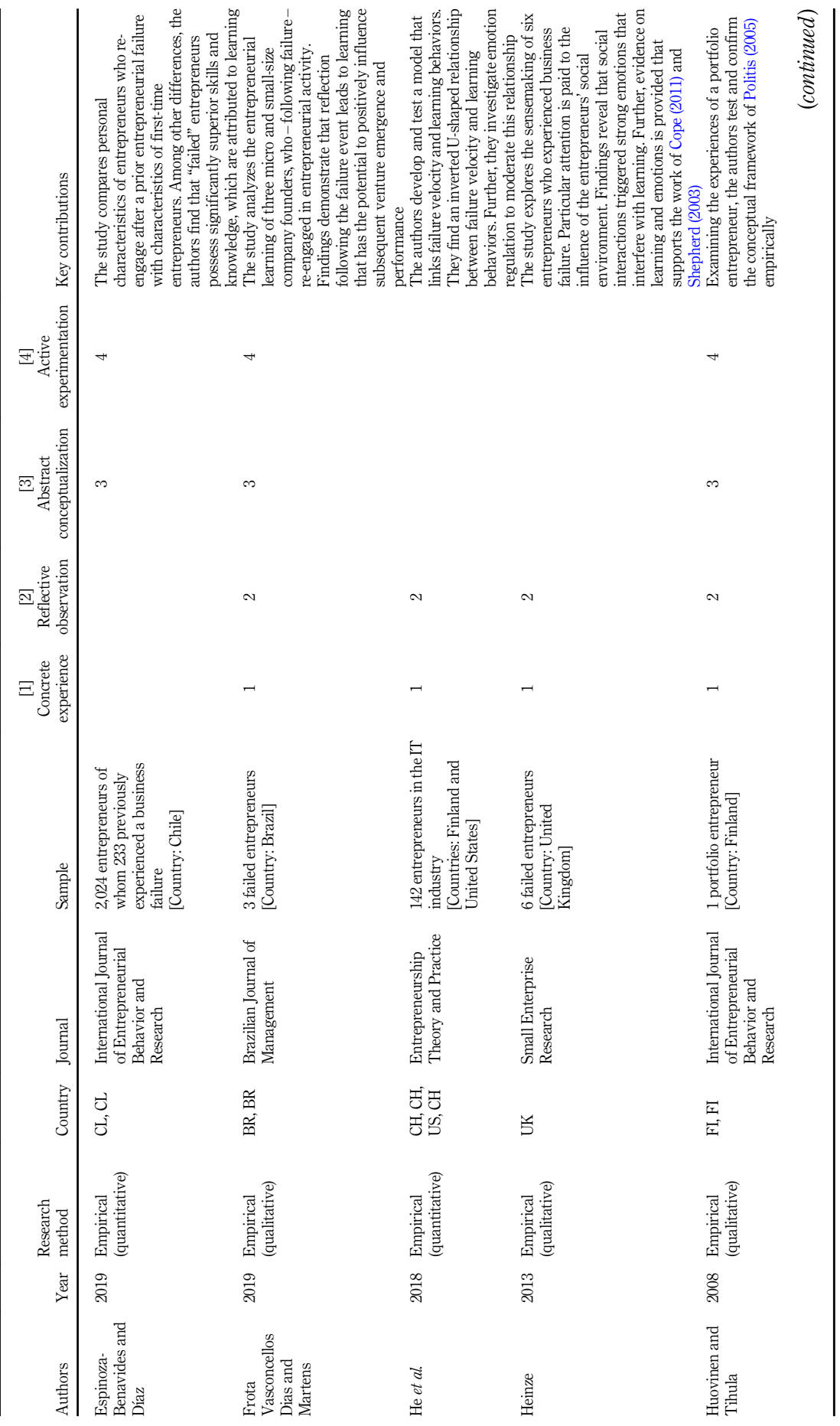

Table 1. 

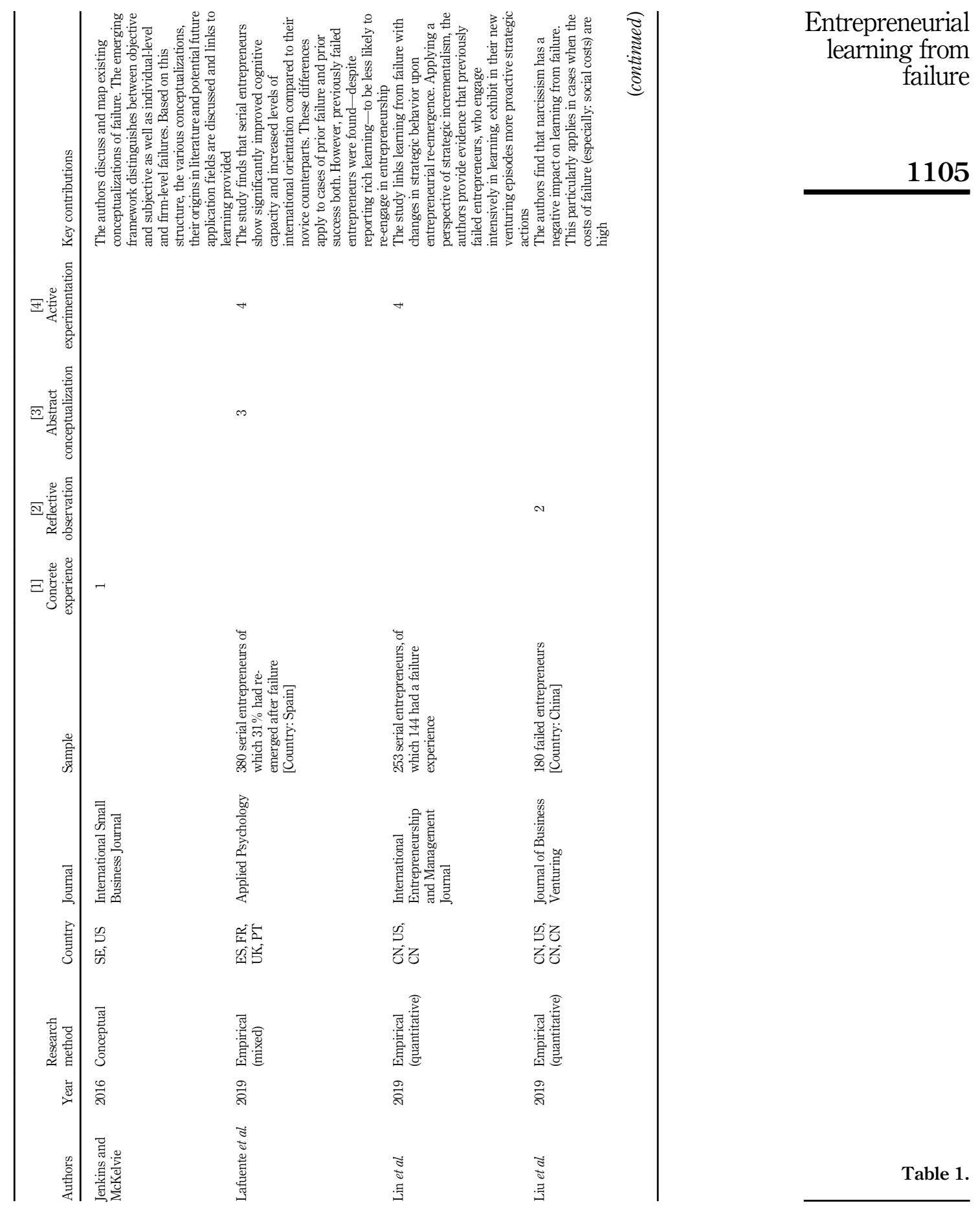

Table 1. 


\begin{tabular}{l} 
IJEBR \\
26,5 \\
$\mathbf{1 1 0 6}$ \\
\hline
\end{tabular}

Table 1.

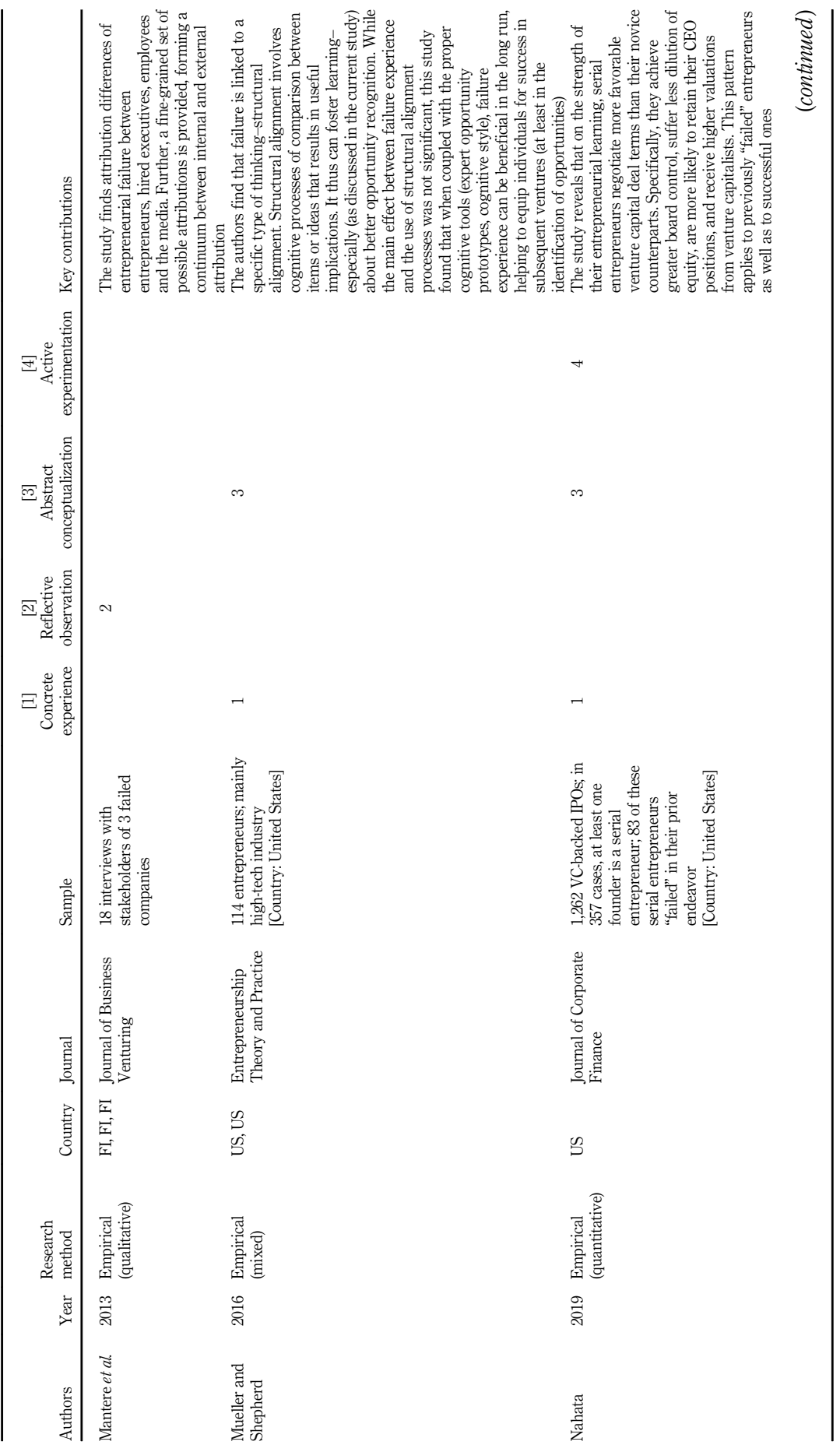




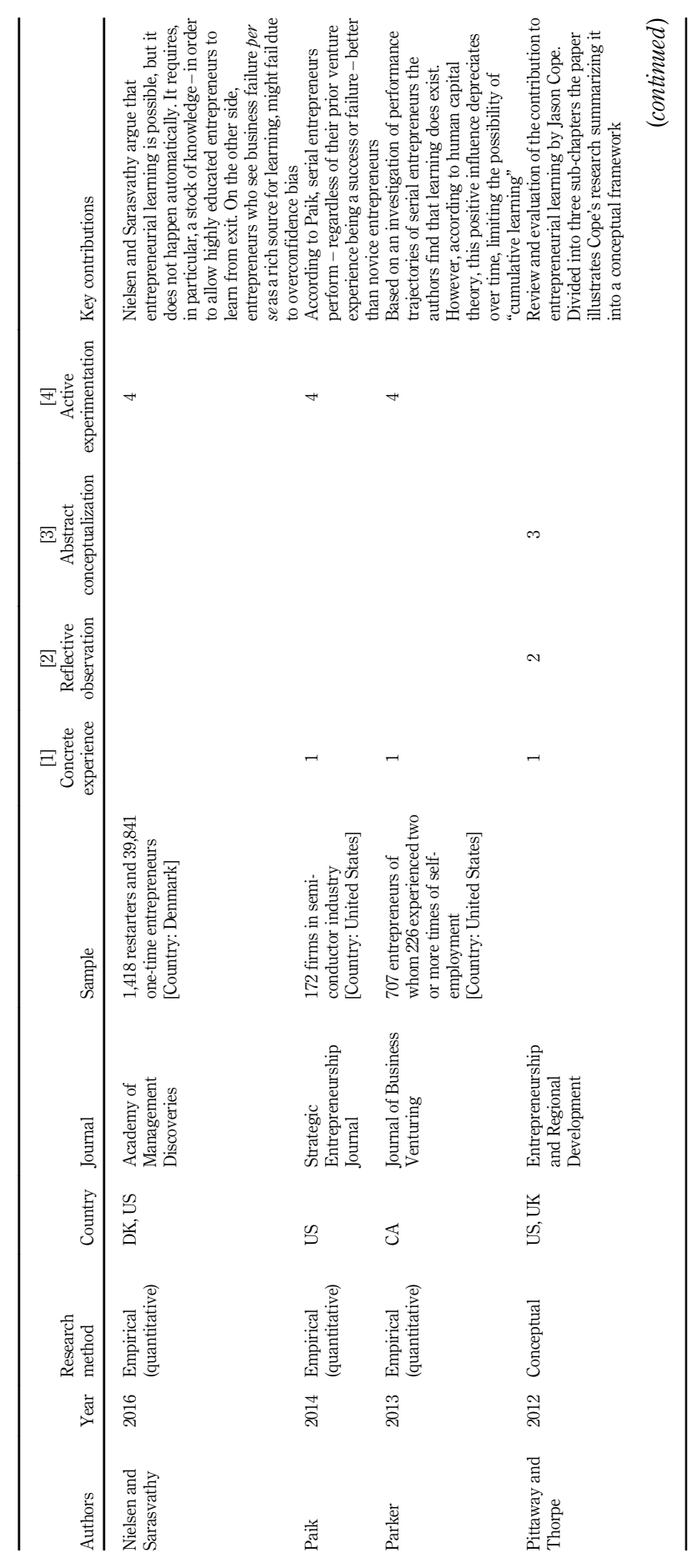

Entrepreneurial learning from failure

1107

Table 1. 
IJEBR
26,5

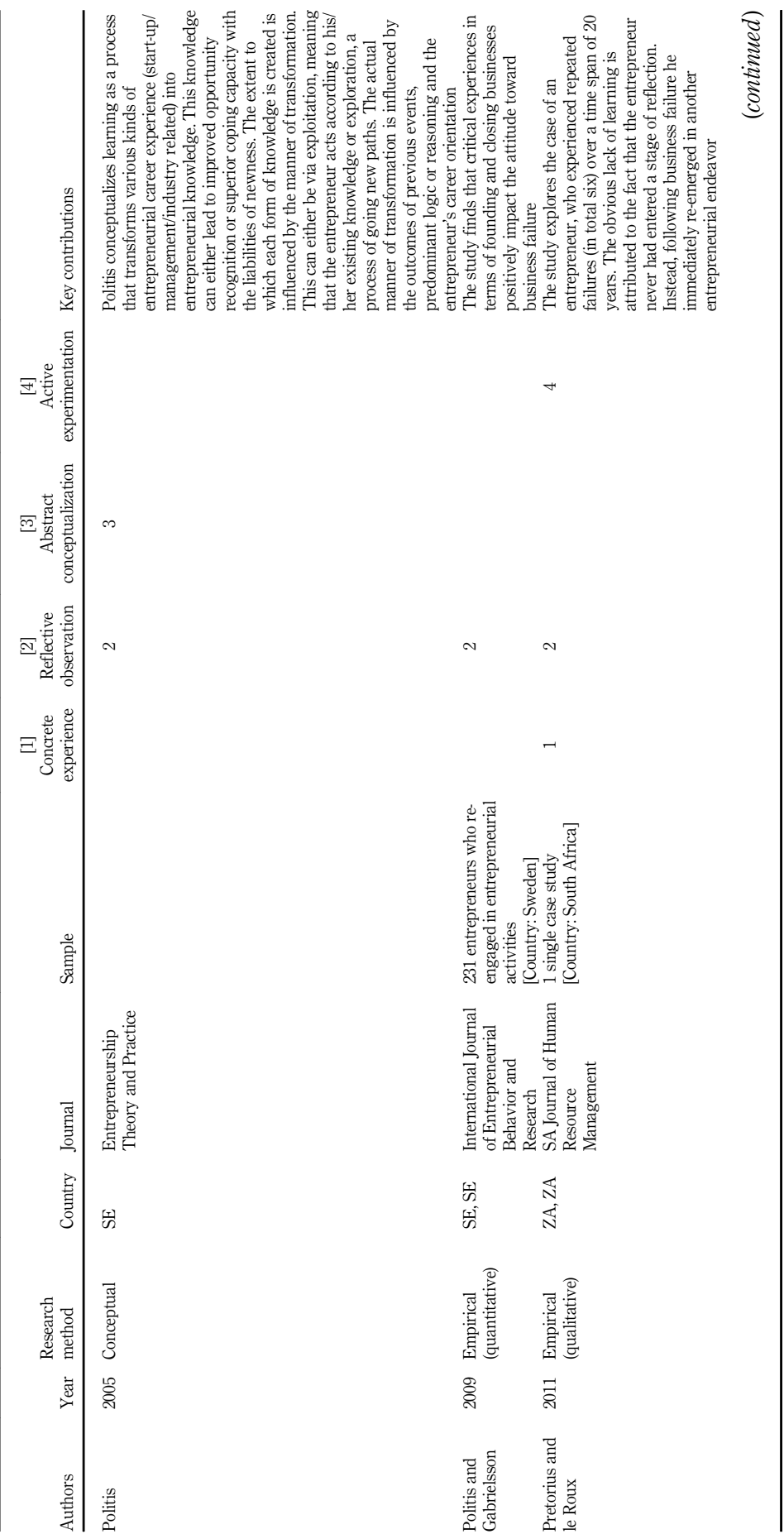

Table 1. 


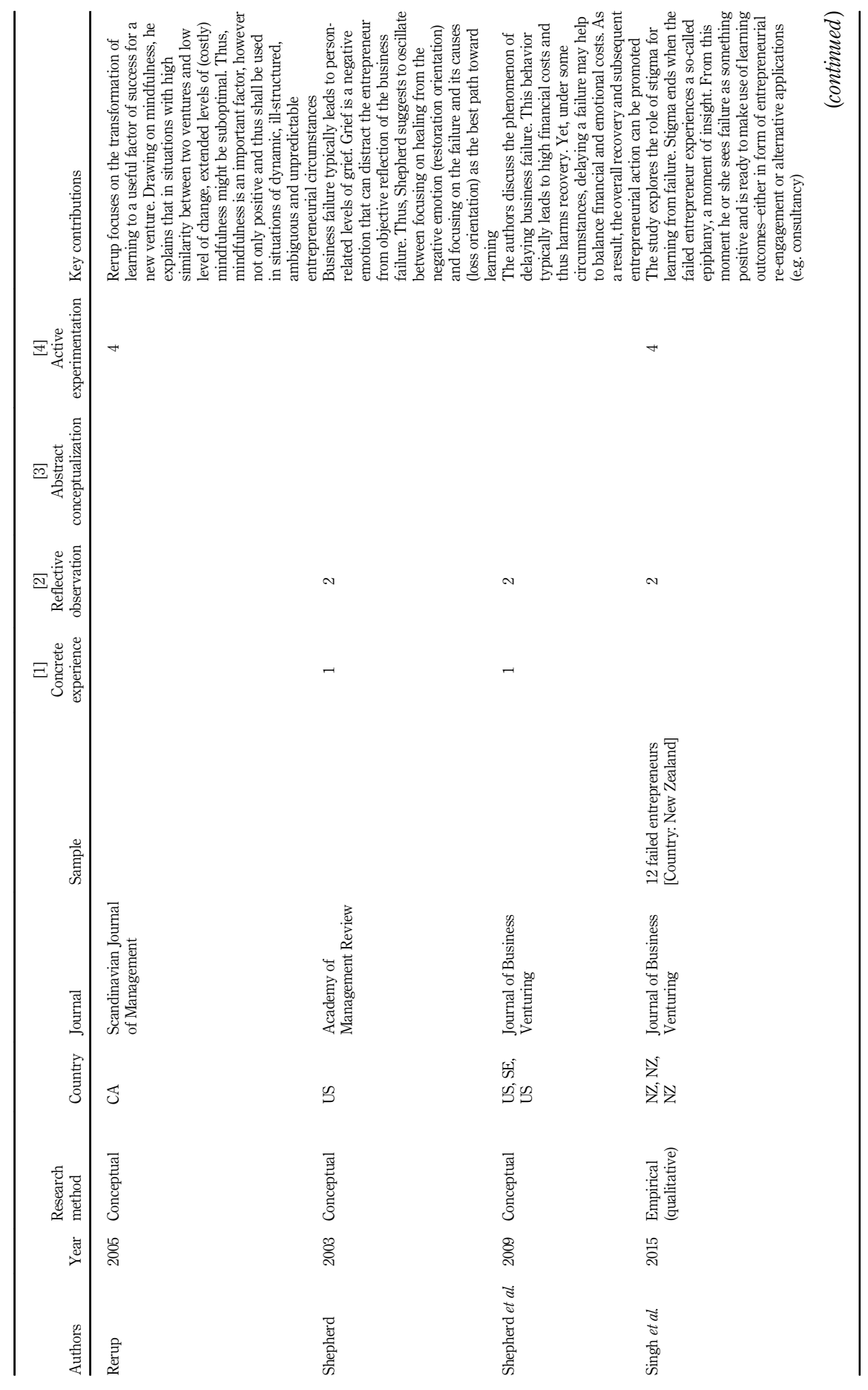

$\begin{array}{r}\begin{array}{r}\text { Entrepreneurial } \\ \text { learning from } \\ \text { failure }\end{array} \\ \mathbf{1 1 0 9} \\ \hline\end{array}$

Table 1. 


\begin{tabular}{l} 
IJEBR \\
26,5 \\
$\mathbf{1 1 1 0}$ \\
\hline
\end{tabular}

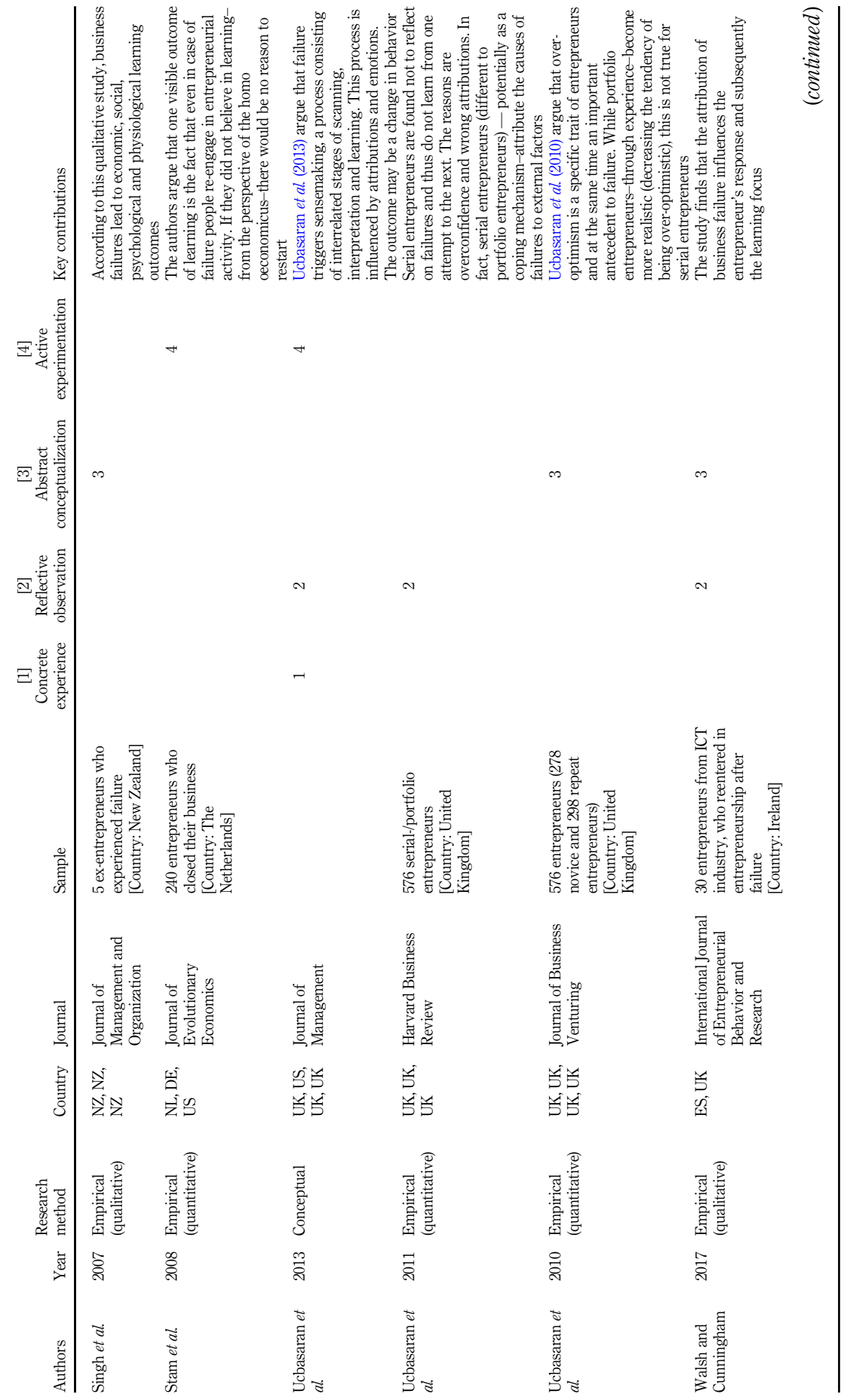

Table 1. 


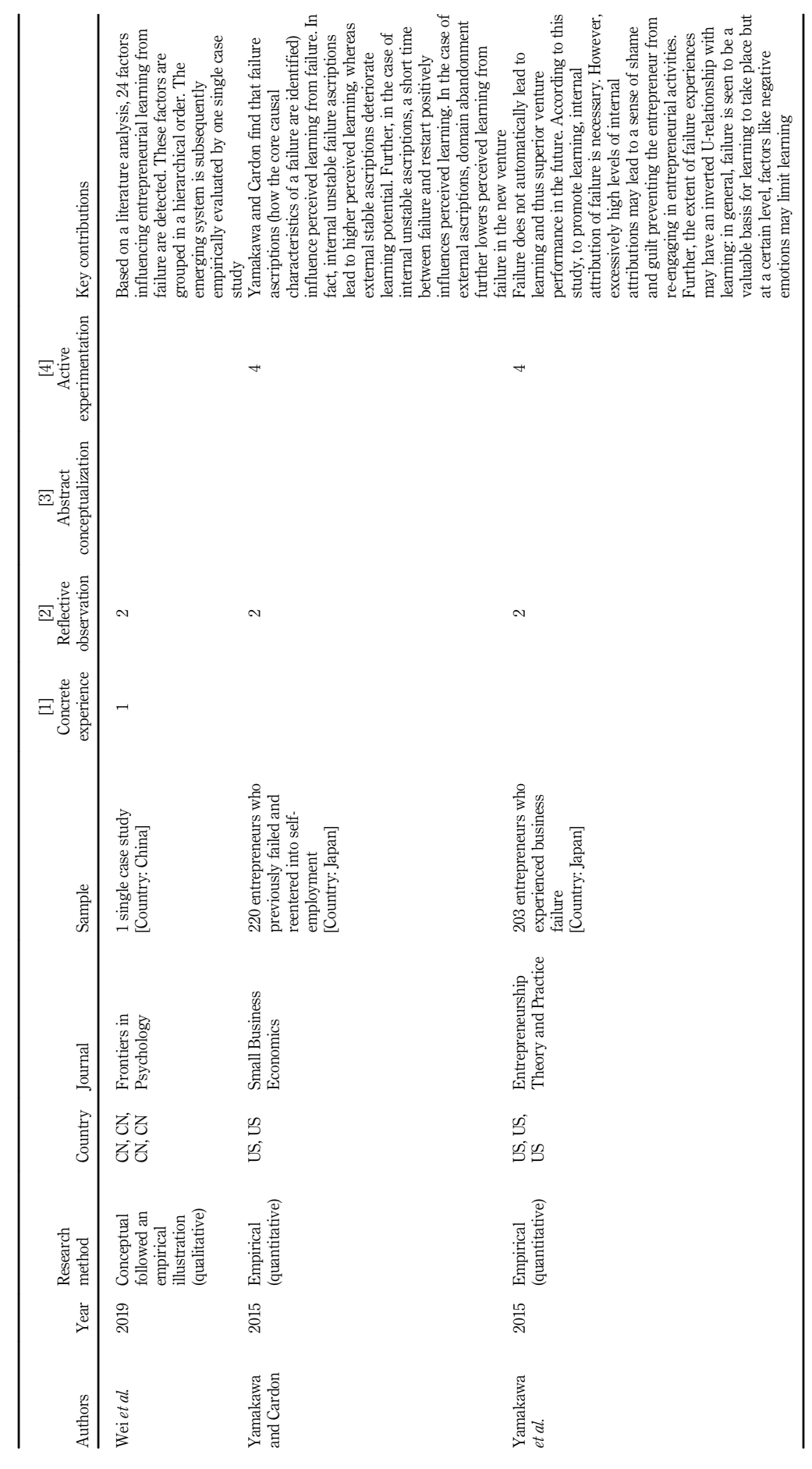
Entrepreneurial learning from failure

1111

Table 1. 
IJEBR

26,5

1112

learning outcomes (Cope, 2011; Dias and Teixeira, 2017; Frota Vasconcellos Dias and Martens, 2019; Heinze, 2013; Pittaway and Thorpe, 2012; Pretorius and Le Roux, 2011; Singh et al., 2007; Ucbasaran et al., 2013) and learning-based behavioral changes upon entrepreneurial re-emergence (Amankwah-Amoah et al., 2018; Lafuente et al., 2019; Lin et al., 2019; Nahata, 2019).

As visible, the contributions of 37 of 40 research studies can be linked to one of the three issues mentioned above. The remaining papers make a very heterogeneous range of contributions, such as clarifying definitional issues (Jenkins and McKelvie, 2016) or proposing conceptual learning frameworks (Politis, 2005) as well as theories of re-emergence (Stam et al., 2008).

A comprehensive list of publications, including their key contributions and other relevant information, is provided in Table 1.

\subsection{Learning process}

In this section, we present the state of research on entrepreneurial learning from failure from an experiential learning perspective, structuring our findings according to the experiential learning process developed by Kolb (1984).

4.5.1 Concrete experience. The failure of an entrepreneurial endeavor is in many cases a highly critical event influencing both the business and the personal life of an entrepreneur (Coad, 2014; Cope and Watts, 2000; Dias and Teixeira, 2017; Huovinen and Tihula, 2008; Shepherd, 2003; Singh et al., 2007). Spheres of impact include financial, emotional, physiological, social, professional and entrepreneurial domains (Cope, 2011; Heinze, 2013; Pittaway and Thorpe, 2012). The actual level of impact depends on the nature of the failure event (e.g. bankruptcy, closure due to sustained losses) and a range of subjective factors determined primarily by the entrepreneur's personality. Indeed, perceptions of failure may vary widely. Shepherd (2003) even sees links between entrepreneurial failure and the loss of a loved person, given the strong bonds between ventures and their owners (Frota Vasconcellos Dias and Martens, 2019; Shepherd, 2003). In contrast, Dias and Teixeira (2017) find that in some cases failure may be experienced as a relief after the stress of the process of descending into failure.

A large number of studies stress the pivotal role of failure as a trigger for learning (e.g. Amankwah-Amoah et al., 2018; Cope, 2011; Eggers and Song, 2015; He et al., 2018; Singh et al., 2007). Drawing on the work of Fiol and Lyles (1985), Cope (2003) states that "shocks, jolts, and crises are necessary for unlearning, new higher-level learning and readaptation to take place." In a later study of eight "failed" entrepreneurs, Cope (2011) illustrates how failure can trigger higher-level learning, resulting in a variety of outcomes (e.g. learning about oneself and about entrepreneurship — for details see stage 3). Yet, as Shepherd (2003) mentions, learning from failure is neither automatic nor instantaneous. It requires specific learning behaviors that occur during subsequent stages of the experiential learning process.

4.5.2 Reflective observation. An entrepreneur who perceives a failure as critical may enter a stage of reflective observation on what has happened. Reflective observation is - in the entrepreneurial context-well captured by the notion of sensemaking articulated in Ucbasaran et al. (2013). Ucbasaran et al. (2013) conceptualize sensemaking as a complex process aimed at giving meaning to occurrences. From a temporal perspective, sensemaking consists of the sub-stages scanning and reflecting. Scanning entails paying selective attention to information regarding the failure (Ucbasaran et al., 2013). Reflecting can be seen as a stage of information processing and attaching meaning to the insights achieved. Pittaway and Thorpe (2012), interpreting Cope's lifetime contribution to the field of entrepreneurial learning, portray reflection as a process of four interrelated activities: looking backward, reminiscing about the experience; looking forward to further possible actions; looking outward to the environment; and looking inward to oneself. 
The importance of reflective observation for experiential learning is illustrated empirically by Pretorius and Le Roux (2011). The authors investigate a 20-year-long entrepreneurial career that consisted of five consecutive business failures. The analysis reveals that the entrepreneur never reflected on these failures but instead directly re-engaged in the next entrepreneurial endeavor. The study finds no evidence of learning behaviors or learning outcomes and thus sees this lack of learning as a main cause for the persistent failing.

The process of reflective observation is influenced by a variety of interrelated cognitive and emotional factors (Schwandt, 2005; Ucbasaran et al., 2013). The literature discusses the role of the individual stock of knowledge, the trait of narcissism, the attribution of the failure to particular causes and the individual emotional patterns for this learning stage.

Stock of knowledge. The nature of experiential learning as experience-based updating of previous knowledge (Kolb, 1984) is visible in the entrepreneurial context. Minniti and Bygrave (2001) equate learning to updating a subjective stock of knowledge. Politis (2005), empirically supported by Huovinen and Tihula (2008), views learning as a transformation of experience into knowledge and also considers the role of pre-existing knowledge for interpretation and reflection. This insight is supported by Mueller and Shepherd (2016), who highlight that the benefits that result from an experience of failure depend on prior knowledge. Specifically, they argue that more experienced entrepreneurs possess more enhanced opportunity prototypes. An opportunity prototype is "a cognitive representation of the ideal business opportunity," which influences the transformation of the experience of failure into knowledge about the process of opportunity identification. In addition, as Politis and Gabrielsson (2009) find, prior start-up and business closure experience may influence an entrepreneur's attitude toward failure, which in turn impacts the reflective observation process.

Narcissism. In their recent quantitative study, Liu et al. (2019) show that narcissism has a strong influence on an entrepreneur's ability and motivation to engage in reflective observation. Narcissism entails an exaggeratedly positive self-view that the individual wishes to maintain. Entrepreneurs with highly narcissistic tendencies might show limited openness to external feedback and apply only selective information scanning mechanisms. Hence, the information they gather about their failures might be limited, both in amount and validity. This phenomenon applies particularly in cases of high social costs. Given the strong need narcissists have to maintain their reputations, they will apply coping mechanisms that limit critical reflection on causes of failure.

Attribution of failure to specific causes. The extent and flow of reflection are significantly influenced by the identification of reasons for the failure (Eggers and Song, 2015; Walsh and Cunningham, 2017; Yamakawa et al., 2015). Mantere et al. (2013) illustrate seven types of failure narratives, of which four were found to be predominantly used by entrepreneurs. These narratives include the acceptance of personal responsibility ("catharsis"), the attribution of irrational behavior to collective hubris in the venture ("hubris"), the "downfall of the entrepreneurial hero" due to externals (e.g. investors) ("nemesis") and unexpected market developments ("fate"). Despite this variety of attributions of failure, research mainly builds on simpler conceptualizations.

Yamakawa and Cardon (2015) distinguish internal, unstable attribution from external, stable attribution. The former refers to a cognitive pattern of blaming oneself for the failure. The entrepreneur finds the cause of failure to be a shortcoming in his or her skills, management expertise or financial planning. Internal attribution enables so-called counterfactual thinking, a type of reflection that enhances the understanding of causeeffect relationships. As a consequence, rich learning can be expected, changing the previously erroneous mindset and rendering the failure cause unstable. In another study, Yamakawa et al. (2015) confirm the potential positive impact of internally attributed failures on reflection.

Entrepreneurial learning from failure 
IJEBR

26,5

1114

However, they highlight that the extent of prior failure experiences influences this relationship. For entrepreneurs who have suffered a high number of failure experiences, internal attribution can limit the ability to reflect. If the entrepreneur, on the other hand, ascribes the failure to external, stable causes, negative emotions (e.g. feelings of shame or grief) can be mitigated (Yamakawa et al., 2015). This, however, implies that he or she perceives failure as a result of unfavorable external conditions like strong competition and environmental uncertainty, limiting the signaling effect of failure and thereby limiting reflection. A group that appears prone to external failure attribution are serial entrepreneurs (Ucbasaran et al., 2011). Despite repeated failure, serial entrepreneurs have been found to adhere to external failure attribution, impeding their learning progress. Walsh and Cunningham (2017) link failure attribution to specific learning outcomes. They explore three different types of failure ascriptions: internal, external and hybrid. Internal failure ascription triggers affective responses leading to person-related learning outcomes - that is, "learning about oneself" (Cope, 2005, 2011). Entrepreneurs who attribute failure to external causes show behavioral changes with regard to venture and network/relationship dimensions. Hybrid approaches combining internal and external ascription lead to cognitive responses with regard to venture management.

Emotional sphere. Failure, as an exceptionally critical event, strongly impacts the entrepreneur's emotional sphere (Dias and Teixeira, 2017; Shepherd, 2003; Shepherd et al., 2009). Failure-induced emotions are manifold and can include grief, regret, disappointment, frustration, pain, remorse, shame, anger, guilt, blame, depression and the development of phobias (Byrne and Shepherd, 2015; Singh et al., 2007, 2015; Ucbasaran et al., 2013). Byrne and Shepherd (2015), drawing on the work of others, highlight that failure may also facilitate positive emotions (e.g. feelings of pride, confidence and enthusiasm). The concrete emotional impact of a failure depends on various factors, such as the entrepreneur's experience, age, perception of blame and degree of resilience (Corner et al., 2017; Shepherd, 2003; Ucbasaran et al., 2013). Further, as Frota Vasconcellos Dias and Martens (2019) stress, emotions related to failure can also be considerably influenced or even triggered by the entrepreneur's social environment (friends, spouse, parents and other family members). The emergence of emotions is a process, and emotions often emerge only at a certain temporal distance from the failure event itself (Heinze, 2013).

Despite the commonly shared awareness of emotional diversity, existing research focuses mainly on one specific form of emotion: grief. This stream was established by Shepherd (2003), who applied psychological insights to the entrepreneurial context. Shepherd argues that grief, as a negative emotional response to failure, may interfere with the entrepreneur's allocation of attention to the causes of failure. Overcoming grief as an obstacle to learning requires efforts in two directions. On the one hand, in the close aftermath of failure, the entrepreneur might feel the need to distract himself or herself from thinking about the loss ("restoration orientation"). Cope (2011) refers to this as an "initial hiatus," a process of stepping back in order to heal emotionally. On the other hand, Shepherd (2003) and Cope (2011) similarly note that from a certain point, active engagement with the failure becomes essential for recovering and learning ("loss orientation"). In addition, Shepherd (2003) argues that founding a new company might also accelerate recovery from failure. However, this manner of coping involves the danger of repeating mistakes due to insufficient learning (Shepherd, 2003; Pretorius and Le Roux, 2011). Instead, “oscillation” between restoration and loss orientation is seen as the ideal path toward recovery and subsequent learning. Reduced grief after stages of restoration orientation may enable the entrepreneur to focus for a time and to a certain extent on the loss before embarking on a further phase of restoration. This dual process continues until the entrepreneur has recovered. The exact time span of an individual's process of recovery from grief varies. Amankwah-Amoah et al. (2018), drawing on a sample of 15 re-emerged entrepreneurs, report on periods of between one and two years. 
Byrne and Shepherd (2015) offer another perspective on the underlying process. The authors asked "failed" entrepreneurs for their overall emotional feeling at the time of failure and after some time had passed. Linking the responses to the respective learning progress, they find that strong negative emotions at the beginning followed by strong positive emotions are the most effective constellation for learning. In this way, the negative emotions trigger deep reflection. The process of reflection (probably via oscillation) enables the entrepreneur to reduce grief and to concentrate on the causes of failure. Yet, as Corner et al. (2017) argue, not every case requires intensive efforts toward recovery. Indeed, their qualitative investigation of the emotional processes of 11 "failed" entrepreneurs revealed that the majority showed resilience, and thus stable levels of functioning, after a severe event. Consequently, there may exist other emotional pathways following a failure that have yet to be explored.

One potential path is described in the work of Singh et al. (2015). In a qualitative study, they found evidence that entrepreneurs felt tainted with stigma - a negative emotion that emerged even prior to the failure and inhibited subsequent reflection. Yet at some point, study participants experienced a so-called "epiphany". This epiphany, defined as a sudden, deep insight into how the entrepreneur himself or herself had contributed to the failure, changed the prior negative emotional state into a positive one and enabled reflective observation.

While there are obviously different views on how emotions should be regulated, studies concur about the pivotal role this process plays in learning (Amankwah-Amoah et al., 2018; Cope, 2011; Shepherd, 2003; Singh et al., 2007; Wei et al., 2019). In cases of multiple failures, He et al. (2018) find that the rate at which failure events are experienced ("failure velocity") influences learning. Failure may, on the one hand, trigger sensemaking while on the other hand generating strong emotions that hinder learning. Consequently, the relationship between failure velocity and learning behaviors follows an inverted U-shape.

4.5.3 Abstract conceptualization. In the stage of abstract conceptualization, the entrepreneur further develops his or her conclusions about the failure experience. Specifically, the insights from the previous stage of reflective observation are linked to existing knowledge to form sound theories (Kolb, 1984). This results in a variety of abstract learning outcomes that are not situation-specific but rather applicable in a range of contexts (entrepreneurship, consulting, mentoring, etc.; Cope, 2011). With regard to the content of the learning, research has found evidence for learning within the personal, social, venture and entrepreneurial spheres (Cope, 2011; Frota Vasconcellos Dias and Martens, 2019; Mueller and Shepherd, 2016; Singh et al., 2007). These findings represent perceived learning outcomes, predominantly derived from in-depth interviews with failed entrepreneurs (Cope, 2011; Frota Vasconcellos Dias and Martens, 2019; Singh et al., 2007).

The personal sphere comprises insights about one's own strengths, weaknesses, skills, attitudes, beliefs and areas for development as well as interests and motivations. Cope's (2011) findings are complemented by a number of further exploratory studies (e.g. Frota Vasconcellos Dias and Martens, 2019; Heinze, 2013). Specific examples of learning have included the consciousness of personal strengths (Cope, 2011), the need to follow one's passion (Heinze, 2013) and the awareness of increased resilience (Frota Vasconcellos Dias and Martens, 2019). Conceptually, Cope (2011) links person-related outcomes to the concept of "transformative learning" (Mezirow, 1991). Transformative learning is a higher-order form of learning with a distinctly personal dimension, able to induce profound changes in "the self" of the entrepreneur (Cope, 2003, 2011; Mezirow, 1991). Walsh and Cunningham (2017) find that this learning outcome appears also in situations of extended grief. However, it depends upon identifying the cause of failure primarily in oneself (Walsh and Cunningham, 2017). This may also reflect reality in many cases, as the failure as a catalyst for transformative learning often is self-imposed (Pittaway and Thorpe, 2012). A sustainable, critical focus on areas for personal (and business) development may lead to what Lindh and Thorgren (2016) 
IJEBR

26,5

call a "continuous reflective ability" and a "better self-view" (Ucbasaran et al., 2010) in the long run.

Learning about social relationships refers to improved insights into the nature and management of social networks inside and outside the venture (Cope, 2011; Frota Vasconcellos Dias and Martens, 2019). The range of network partners is wide, including, for example, the entrepreneurial team, employees, customers, suppliers, competitors, advisory agencies and support services. Better understanding of and ability to handle social ties may enhance the ability to spot and seize entrepreneurial opportunities (Politis, 2005).

Venture-related learning outcomes relate to an enhanced understanding with reference to the (former) enterprise's strengths, weaknesses, opportunities and threats (Cope, 2005, 2011; Espinoza-Benavides and Díaz, 2019; Frota Vasconcellos Dias and Martens, 2019). Moreover, entrepreneurs may gain a clearer picture of internal business needs, requirements for growth and future strategic directions (Cope, 2005; Lafuente et al., 2019; Lin et al., 2019). These outcomes result from "double-loop learning", a means of higher-level learning enabling a renewed understanding or redefinition of organizational processes and strategies (Cope, 2011).

Learning about entrepreneurial activities refers to entrepreneurial tasks in a narrower sense (recognizing opportunities, coping with the liabilities of newness) as well as to more general venture management activities. The formers are discussed in a conceptual work by Politis (2005), who sees improvements in opportunity recognition and liability handling as primary outcomes of entrepreneurial learning. This conceptualization of entrepreneurial learning has been applied empirically by Huovinen and Tihula (2008). Mueller and Shepherd (2016) find further evidence that learning from failure may lead to improved abilities of opportunity identification. This, however, requires the use of proper cognitive tools, such as a certain style of sensemaking (Mueller and Shepherd, 2016). Among general venture management activities, better capabilities in negotiating with venture capitalists (Nahata, 2019) and acting effectively under pressure and tension are thematized (Frota Vasconcellos Dias and Martens, 2019). Conceptually, learning about venture management can be linked to Gibb's (1997) concept of "generative learning," implying that the entrepreneur may become more proactive in future venturing decisions (Cope, 2011).

4.5.4 Active experimentation. Previously failed entrepreneurs may choose among a variety of ways to actively experiment with their newly acquired learning outcomes. Indeed, research stresses that, besides further entrepreneurial activity, there are other options, like consulting and networking, through which a "failed" entrepreneur can utilize and test his or her knowledge base (Cope, 2011; Singh et al., 2015). However, empirical studies are mostly concerned with entrepreneurial re-engagement (e.g. Amankwah-Amoah et al., 2018; Boso et al., 2019; Espinoza-Benavides and Díaz, 2019; Nielsen and Sarasvathy, 2016; Yamakawa and Cardon, 2015; Yamakawa et al., 2015). Specifically, they attempt to understand why certain individuals (and not others) decide to actively experiment via re-engagement (e.g. Nielsen and Sarasvathy, 2016; Stam et al., 2008) as well as to determine how and when this application of knowledge is executed (e.g. Amankwah-Amoah et al., 2018; Huovinen and Tihula, 2008; Rerup, 2005). Moreover, research focuses on specific behavioral changes upon re-emergence, including modified strategic actions (Lin et al., 2019), negotiation behavior with venture capitalists (Nahata, 2019) and internationalization (Lafuente et al., 2019). Further, scholars attempt to measure the degree of success that is derived from learning (e.g. Paik, 2014; Yamakawa et al., 2015).

The question of why "failed" entrepreneurs decide to enter the stage of active experimentation via entrepreneurial re-emergence has attracted considerable research interest (Nielsen and Sarasvathy, 2016; Stam et al., 2008; Ucbasaran et al., 2010, 2013). Stam et al. (2008) stress learning as the primary reason for restarting entrepreneurship when a 
previous attempt has failed. While assumed learning may not in itself be enough, in many cases, to prompt an entrepreneur to decide to re-emerge (Lafuente et al., 2019), learning, taken in conjunction with overconfidence and a lack of other employment opportunities, has been found to drive most re-engagement decisions (Nielsen and Sarasvathy, 2016; Ucbasaran et al., 2010, 2013). In addition, Amankwah-Amoah et al. (2018) highlight the role of family as a supporting factor. Eggers and Song (2015) as well as Yamakawa et al. (2015) see a connection between the primary direction of failure ascription and motivation for a restart. They argue that external failure ascription might lead to a higher probability of re-engagement. In the opposite case (internal failure ascription), entrepreneurs might see themselves as not being talented enough and therefore refrain from re-engagement. This insight may be linked to the finding of Singh et al. (2015) that the feeling of stigma needs to be overcome prior to entering the experimentation stage.

Recognizing that the mindful application of prior experience is essential for successful future venture performance (Rerup, 2005), research analyzes patterns of re-engagement behaviors. In particular, the question of when and how active experimentation takes place has been of interest. Dias and Teixeira (2017) stress that failure appears to have a significant impact on how entrepreneurs design their re-emergence. Specifically, "failed" serial entrepreneurs tend to change industries when opening another business (Eggers and Song, 2015). This decision can be traced back to external failure attribution, which may lead entrepreneurs to change the context but retain the same management style. As a result, lessons learned may be unfavorably applied, leading to poor firm performance (Eggers and Song, 2015; Pretorius and Le Roux, 2011). Other studies find that, on the strength of their learning, entrepreneurs show a stronger tendency toward internationalization (Lafuente et al., 2019) and more proactive strategic behavior upon re-emergence (Lin et al., 2019).

The question of whether, and under what circumstances, learning from failure can lead to successful entrepreneurial re-emergence has generated considerable research interest (Boso et al., 2019; Eggers and Song, 2015; Huovinen and Tihula, 2008; Liu et al., 2019; Paik, 2014; Parker, 2013; Yamakawa and Cardon, 2015; Yamakawa et al., 2015). Apart from Huovinen and Tihula (2008), who illustrate through a single case study how learning affects the process of forming an entrepreneurial team, all the other studies cited above apply quantitative methods. Success is measured either by venture performance indicators (growth: Eggers and Song, 2015 as well as Yamakawa et al., 2015; profits: Parker, 2013; survival: Paik, 2014; subjective performance: Boso et al., 2019) or perceived learning (Liu et al., 2019; Yamakawa and Cardon, 2015). Empirical evidence predominantly suggests that failures can indeed lead to learning-based improvements upon entrepreneurial re-emergence (e.g. Boso et al., 2019; Paik, 2014; Parker, 2013; Yamakawa and Cardon, 2015). However, this mechanism is subject to a number of conditions and limitations. For example, Yamakawa and Cardon (2015) find more perceived learning in cases of internal failure ascription. Parker (2013) discovers a depreciation effect of learning benefits over time. Eggers and Song (2015) are critical about the learning of serial entrepreneurs, who are frequently seen to blame external factors for their failures and to change industries upon re-emergence. To sum up, large-scale empirical data support the view that learning from failure is possible but at the same time highlights several factors that were already familiar from conceptual and qualitative studies.

\section{Discussion and future research}

This review aims to take stock of research on entrepreneurial learning from failure and to identify promising avenues for future research. Existing knowledge, which appears to be fragmented, is mapped in the light of experiential learning theory. Utilizing Kolb's (1984) experiential learning model, we assign and structure the literature according to four stages of learning (see Table 2) that range from the initial experience of business failure to the eventual application of lessons learned in, for example, a new entrepreneurial episode. This theory- 


\begin{tabular}{l} 
IJEBR \\
26,5 \\
$\mathbf{1 1 1 8}$ \\
\hline
\end{tabular}

Table 2.

Overview of the current state of research

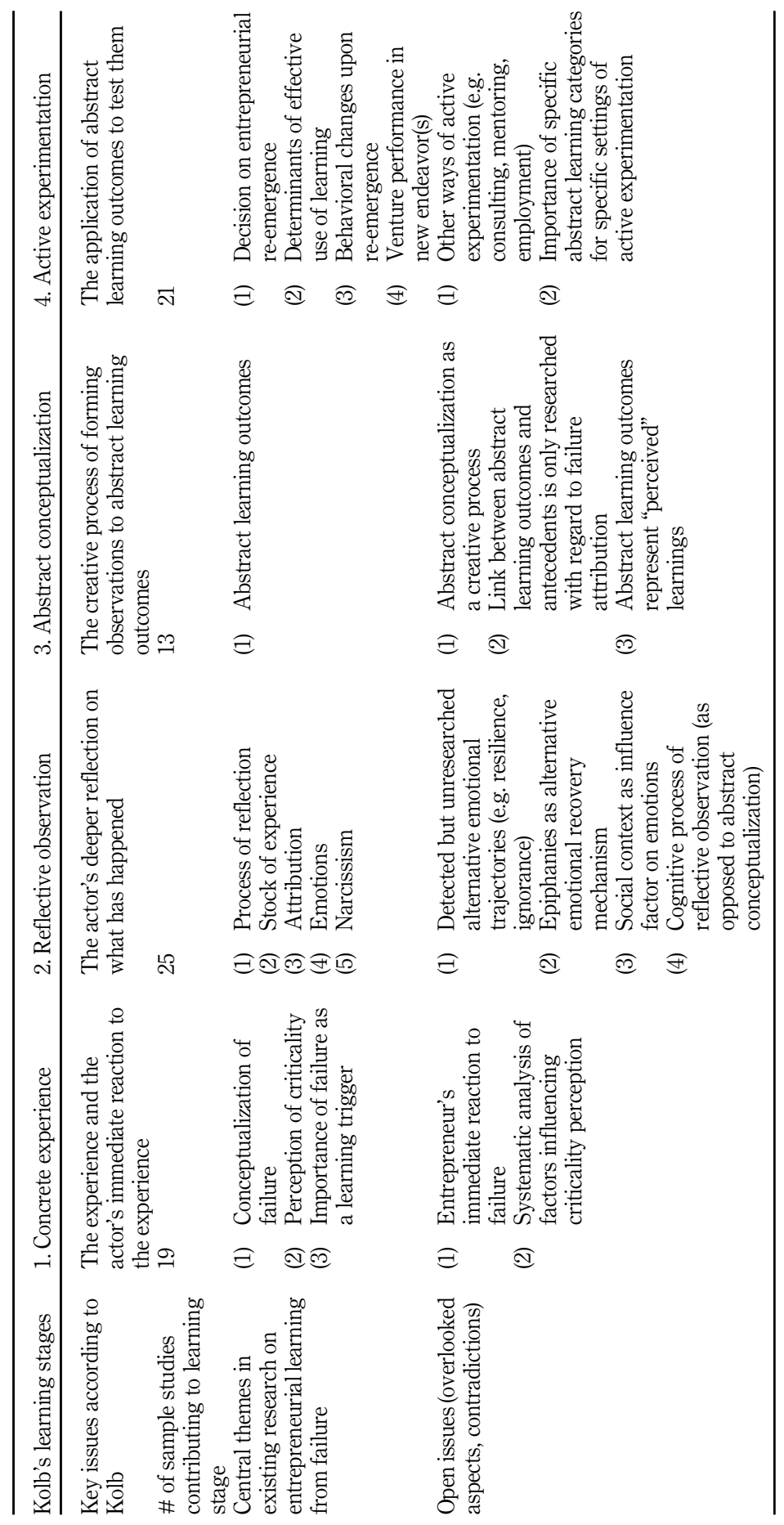


guided approach allows scholars to systematically detect overlooked questions and Entrepreneurial contradictions within existing research.

According to Kolb (1984), the first learning stage starts with the "concrete experience." In the context of this study, this stage comprises the business failure and the entrepreneur's immediate reaction to this event. Regarding failure itself, existing knowledge is rather comprehensive and concerns conceptual issues (Jenkins and McKelvie, 2016) as well as the criticality of such events and the potential they create for learning (Cope, 2011). Previous research shows substantial individual differences in perceptions of failure (Dias and Teixeira, 2017; Frota Vasconcellos Dias and Martens, 2019). Nevertheless, there is broad agreement that it is not the event itself that determines how critical a business failure is but rather how it is perceived subjectively and the individual attitude taken to the failure (Cope, 2011; Ucbasaran et al., 2013). Mainly drawing on its criticality, research appears convinced of the learning potential that failure bears (e.g. Amankwah-Amoah et al., 2018; Cope, 2011; Eggers and Song, 2015; He et al., 2018; Singh et al., 2007). Regarding the entrepreneur's immediate reaction to failure, however, knowledge is limited.

Based on these findings, two important avenues for future research emerge. First, investigating the entrepreneur's immediate reaction (cognitive, emotional, activity-oriented) to business failure appears relevant, as different reactions can lead to different coping strategies and processes of emotional recovery (Byrne and Shepherd, 2015). Contrasting the immediate reaction and the later process of reflection may enable researchers to detect trajectories that have an explanatory character for subsequent learning outcomes. A study of these trajectories should preferably apply a longitudinal research design. Second, research is needed to better understand the determinants that shape the perception of the criticality of business failure. As a starting point, the papers by Lindh and Thorgren (2016) and Morris et al. (2012) may elucidate critical event recognition in the entrepreneurial context. Morris et al. (2012, p. 19), for instance, suggest that the significance of an event is "a function of an event's novelty, expectedness, and consistency with the individual's assumptions and knowledge base." Further research linking the entrepreneur's identity and biography with the recognition of business failure could prove illuminating in this regard.

The second stage in Kolb's learning process, "reflective observation," features the deliberate and detailed sensemaking of the experience. With 25 studies in our sample exploring aspects of this stage, the stage of reflective observation is the one that has attracted the most scholarly attention so far. Studies frequently utilize "reflection" as an umbrella term that covers reflective observation and abstract conceptualization. In most studies, knowledge of reflection has emerged as a side product, as research endeavors are mainly concerned with particular factors (such as emotions or attribution) influencing reflective observation (Eggers and Song, 2015; Huovinen and Tihula, 2008; Liu et al., 2019; Shepherd, 2003). A prominent part of such studies is dedicated to the role of emotions in the process of recovery from failure. Mostly, they are concerned with the recovery from grief (Cope, 2011; Shepherd, 2003). Singh et al. (2015) offer an alternative path to emotional recovery that builds on the abolition of stigma. In addition, a number of scholars provide evidence for alternative reactions such as emotional resilience or immediate re-engagement in a new entrepreneurship episode (Corner et al., 2017; Pretorius and Le Roux, 2011). To a limited extent, these studies also provide links to other influencing factors and later learning outcomes (e.g. Walsh and Cunningham, 2017).

Our analysis reveals at least four avenues for future research on reflective observation. The first one concerns alternative trajectories of the influence of emotional factors. Corner et al. (2017) found patterns of resilience that lead to a different emotional impact and development pattern. An explanatory, longitudinal study that examines the individual's emotional status and its impact on willingness and ability to reflect could unveil the existence of a variety of different trajectories for how emotions and reflection interact over time. Another related phenomenon to be analyzed is the pattern of immediate entrepreneurial re- 
IJEBR

26,5 emergence without reflective observation (as shown by Pretorius and Le Roux, 2011). Specifically, it appears interesting that a lack of emotional impact or a deliberate decision to overcome negative emotional feelings might drive the immediate entrepreneurial reemergence. Second, the concept of a process of critical reflection that requires oscillation between managing negative emotions and reflecting on the failure (Cope, 2011) appears to conflict with the concept of epiphanies (Singh et al., 2015). A qualitative study could compare these mechanisms, considering the spheres of emotion, reflection and learning. Third, we encourage future researchers to heed the call issued in several studies (e.g. Cope, 2011; Jenkins and McKelvie, 2016; Liu et al., 2019) to examine the role of the social environment (e.g. the family) on reflective observation. This should include the influence on the perception of failure and the emotional response of the entrepreneur. Fourth, the field would benefit from a better understanding of the cognitive process that constitutes reflective observation in a narrower sense. Apart from certain influencing mechanisms (e.g. emotions), reflection still remains a "black box," which limits our understanding of entrepreneurial learning. The research design of such a study could be geared to those of comparable prior endeavors (Cope, 2003, 2011; Shepherd, 2003; Shepherd et al., 2009).

"Abstract conceptualization", the third stage in the entrepreneurial learning process, entails the transformation of insights on the specific experience into sound abstract learning outcomes. In the context of entrepreneurial learning from failure, this stage is clearly underresearched. In particular, the question of how failed entrepreneurs transform their observation of an experience into abstract learning is largely unanswered. Existing research on reflection (Cope, 2011; Pittaway and Thorpe, 2012) and sensemaking (Ucbasaran et al., 2013) from failure may provide some insights. However, this research fails to elaborate on the differences between the more reflective process of building a perception of an experience and the creative process of transforming this perception into abstract knowledge (Kolb, 1984). Pertaining to the resulting abstract knowledge - that is, the specific content of the learning - a number of qualitative studies found evidence for learning within the personal, social, venture and entrepreneurial spheres (Cope, 2011; Frota Vasconcellos Dias and Martens, 2019; Mueller and Shepherd, 2016; Singh et al., 2007). However, these findings consider perceived learning outcomes. As we know from the literature of learning in educational contexts, perceived and actual learning can vary dramatically (Bacon, 2016). This difficulty likely also applies in the context of entrepreneurial failure, given the potential for biases stemming from failure attribution, stigmatization, emotional coping and optimism. As Nielsen and Sarasvathy (2016) argue, failure can lead to overconfidence, with the founder erroneously believing the failure was a valuable learning experience. Consequently, the entrepreneur may encounter repeated failures due to inaccurate perceptions of his or her own learning (Pretorius and Le Roux, 2011). Other factors that have to be kept in mind when interpreting reported learning outcomes are the elapsed time between failure and data collection as well as any eventual entrepreneurial re-emergence. Existing research builds on rather heterogeneous cases: for example, in the study by Heinze (2013), interviews were conducted between six months and nine years after the failure event; in the study by Cope (2011), one of eight studied entrepreneurs had re-emerged at the time of the interview.

To advance our knowledge on this learning stage, we especially encourage future researchers to shed light on the creative process of transforming experience-based insights into logical, sound concepts. So far, little is known about how abstract learning outcomes emerge, which is an important cornerstone for fully understanding entrepreneurial learning (Kolb, 1984). As far as the influencing factors are concerned, some aspects that play an influential role in the second stage (e.g. stock of knowledge, narcissism) may also be relevant for abstract conceptualization. Given the creative dimension of this process (Kolb, 1984), additional influencing factors (e.g. capacity for abstract thinking, creativity) may play key roles. Furthermore, research might follow the example of Walsh and Cunningham (2017) and try to 
identify links between particular influencing factors and subsequent learning outcome dimensions. With respect to the potential deviations between perceived and actual learning, we do not see a clear direction toward a reliable and valid method of capturing of actual learning outcomes. However, we encourage future researchers to pay closer attention to the credibility of learning outcomes by not only presenting learning contents but also investigating whether the reasoning leading to these contents appears credible. One example of this procedure can be found in Nielsen and Sarasvathy (2016, p. 262), who critically evaluate a statement by a failed entrepreneur and question whether he had "learned the right lesson."

The fourth stage of Kolb's learning process is "active experimentation"-that is, the application of learning outcomes in practice. Research on entrepreneurial learning from failure (e.g. Cope, 2011) recognizes that there are several possible work settings apart from entrepreneurship in which to apply and test abstract learning. However, empirical studies exclusively target the case of entrepreneurial re-emergence (i.e. starting a new entrepreneurial episode). This stream of research flows into four directions. First, scholars are concerned with the question of whether and under what conditions "failed" entrepreneurs decide to reemerge. Presumed learning effects (Stam et al., 2008), overconfidence (Nielsen and Sarasvathy, 2016; Ucbasaran et al., 2010, 2013), family support (Amankwah-Amoah et al., 2018) and failure ascription (Eggers and Song, 2015; Yamakawa et al., 2015) are identified as factors that influence this decision. Second, the process of transferring abstract knowledge to practical settings is of interest-in particular, the degree of mindfulness in knowledge transfer (Rerup, 2005) and the choice of industry and time for re-emergence (Eggers and Song, 2015; Parker, 2013). Third is a very recent research stream focusing on specific behavioral changes upon re-emergence, such as an increased tendency toward internationalization (Lafuente et al., 2019), proactive strategic actions (Lin et al., 2019) and improved negotiating with venture capitalists (Nahata, 2019). While studies within this stream focus predominantly on the outcome (behavioral changes) and less on the learning process leading to this outcome, they reveal the potential of seeking a more detailed view of how learning influences future behavior. Fourth, scholars attempt to evaluate whether and under what circumstances the application of learning is successful. Findings predominantly support the view that failure can lead to learning and successful entrepreneurial re-emergence. However, there are at least two limitations to be highlighted. One is that studies unanimously stress that this learning mechanism is subject to a number of conditional factors. Another is that learning success is measured via either self-reporting or venture performance indicators (e.g. growth, profit, survival). Hence, as discussed above, self-reported learning builds on learning perceptions that may deviate from actual learning. Taking venture performance indicators as proxies for learning risks neglecting explanatory factors for venture success (e.g. social networks).

Future research is required to broaden the field of inquiry to encompass alternative processes of active experimentation. These could include employment as opposed to entrepreneurship as well as mentoring and consulting activities. With regard to concrete research aims, existing work on entrepreneurial re-emergence may act as a map offering orientation (i.e. reasons for re-emergence, transfer process, evaluation of learning). In addition, we advocate a fine-grained analysis on the level of learning categories. Not every learning category (e.g. person-related, entrepreneurship-related) or concrete outcome (e.g. awareness of susceptibility to stress; knowledge of the start-up process) may be relevant in every experimentation setting. Recognizing the links between specific learning categories and success in active experimentation may improve our understanding of the kinds of learning that are important for different kinds of re-emergence. Finally, we encourage scholars to follow the example of Lafuente et al. (2019), Lin et al. (2019) and Nahata (2019) and provide more fine-grained research on concrete learning-induced behavioral changes. To further increase the contribution made by such studies, it might be valuable to qualitatively explore the entire (learning) process leading to the modified behavior. 
IJEBR 26,5

\section{2}

\section{Research questions}

\section{Stage 1: Concrete experience}

- How do entrepreneurs initially react when they face business failure (cognitively, emotionally, activityoriented)? Are these immediate reactions different from later coping and emotional recovery processes? Which patterns of trajectories exist between initial and later reactions? How do these trajectories influence abstract learning outcomes?

- see also: Corner et al. (2017)

- Which factors do influence the perceived criticality of a business failure? How does failure perception differ in diverse geographic and/or cultural contexts?

Stage 2: Reflective observation

- Which alternative trajectories to emotional recovery from failure do exist? Which forms do they take? How do they influence the reflective observation of the failure? What determines which trajectory is pursued? - see also: Corner et al. (2017)

- What are the reasons for skipping the stage of reflective observation via an immediate entrepreneurial reemergence? Is this pattern a deliberate coping mechanism or the result of a lack of emotional impact? - see also: Pretorius and Le Roux (2011)

- How do Cope's (2011) critical reflection and Singh et al.'s (2015) concept of epiphanies relate to each other? What are the differences regarding abstract learning outcomes? - see also: Singh et al. (2015)

- What role does the entrepreneur's social environment (e.g. family, friends) play in the stage of reflective observation? Specifically, how does the social environment influences cognitive and emotional processes? - $\quad$ see also: Cope (2011); Jenkins and McKelvie (2016); Liu et al. (2019)

- What cognitive processes constitute the process of reflective observation on business failure in a narrower sense? - see also: Kolb (1984); Walsh and Cunningham (2017)

Stage 3: Abstract conceptualization

- How do entrepreneurs transform their failure-based observations into logically sound theories (abstract conceptualization)? What influences this process?

- see also: Kolb (1984)

- What distinguishes reflective observation and abstract conceptualization when learning from a business failure?

- see also: Kolb (1984)

- How are specific influence factors on abstract conceptualization linked to subsequent learning outcomes?

- How do abstract learning outcomes, which result from individual perceptions, relate to actual learning?

- $\quad$ see also: Nielsen and Sarasvathy (2016, p. 262), who critically evaluate the reliability of a (reported) perceived learning outcome

Stage 4: Active experimentation

- What determines which setting of active experimentation (e.g. entrepreneurship, employment) is chosen by a previously failed entrepreneur?

- see also: Singh et al. (2015); Walsh and Cunningham (2017)

Table 3.

Research questions for future research endeavors

- How are abstract learning outcomes transferred to subsequent activities? Which factors do influence this process?

- Which abstract learning outcomes are perceived as particularly important/unimportant in specific settings of active experimentation? (e.g. start-up-knowledge may be more relevant for entrepreneurial re-emergence than for employed work) 
order to advance our knowledge. In this regard, we advocate for a better adaption of methodological approaches to the longitudinal character of learning from failure. This issue has frequently been raised in existing research (Cope, 2011; He et al., 2018; Ucbasaran et al., 2010; Yamakawa and Cardon, 2015). It is particularly pertinent to qualitative studies, which are prone to recall biases due to single interviews targeting an entire venturing, failing and learning process (Podsakoff and Organ, 1986). Future research should — at a minimumutilize quasi-narrative interview designs to take advantage of narration-based recall advances (Flick, 2018). However, for studies covering longer periods (e.g. the whole process of learning from failure), a design with two or three data collection points is preferable (Holland et al., 2006; McLeod, 2003).

To sum up, research in its present state offers considerable knowledge of how entrepreneurs learn from failure. However, our analysis has also unveiled a number of blind spots in the research, measurement problems and partly contradictory findings. In general, one may conclude that the earlier stages of the learning process (the failing and the reflective observation on what has happened) have received more attention and study than the later stages (abstract conceptualization and subsequent application of learning outcomes). As a consequence, future research on the earlier stages will build pre-knowledge but will still need to target blind spots and inconsistencies. A fuller understanding of the later stages of the learning process demands broad, exploratory endeavors that particularly target the process of abstract conceptualization and application of knowledge. In sum, one may conclude that learning from failure provides a range of areas for future research. We therefore encourage future researchers to maintain the recent interest in this field, as it yields open questions that are both interesting for research and relevant for practice.

\section{Practical implications}

This review yields important implications for entrepreneurs and policy makers. Entrepreneurs should accept failure as an inherently entrepreneurial phenomenon (Amankwah-Amoah et al., 2018; Cope, 2011; Li et al., 2019). While failure is a critical event that can cause a range of negative effects (e.g. financial, psychological and physiological problems; Byrne and Shepherd, 2015; Shepherd et al., 2009), it also represents an opportunity for learning (Boso et al., 2019; Cope, 2011; Dias and Teixeira, 2017; Espinoza-Benavides and Díaz, 2019; Li et al., 2019). This learning enables growth in individual knowledge that can play a significant role in the success of subsequent (entrepreneurial or other) endeavors (Amankwah-Amoah, 2018; Boso et al., 2019; Paik, 2014; Parker, 2013). Consequently, entrepreneurs should see failure neither as the ultimate end of their entrepreneurial careers (Boso et al., 2019) nor as a proof of being unsuited to entrepreneurship (Lafuente et al., 2019). However, our findings also support the notion that learning from failure does not happen automatically (Shepherd, 2003). Entrepreneurs must consciously manage their negative emotions and engage in critical reflection (Cope, 2011; Shepherd, 2003; Ucbasaran et al., 2013). This implies, also, that they should not unreflectively blame the external environment or bad luck as primary causes of failure but rather mindfully transfer learning outcomes to new endeavors (Yamakawa et al., 2015). Policy makers may be stimulated by our findings on their role in facilitating the use and transfer of the knowledge that results from failure-based learning. In a narrow sense, policy should support the transfer of knowledge between successive entrepreneurial episodes. Our implications for the individual (i.e. that learning is possible and that failure is no sign of inadequacy for entrepreneurship) suggest that policy makers should strive to support the re-emergence of previously failed entrepreneurs as they support first-time entrepreneurs (Lafuente et al., 2019). This requires them to combat the existing social stigma attached to failure, as it could prevent entrepreneurial re-emergence (Singh et al., 2015). Moreover, policy makers should facilitate the development of institutions

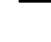


IJEBR

26,5

1124

and initiatives that support failed entrepreneurs in their re-engagement (Boso et al., 2019), such as specialized accelerator programs. In a wider sense, policy makers should ensure that lessons learned from failure are spread across the entrepreneurial community and the society (Cope, 2011). For example, other entrepreneurs could learn from the failures of their peers in self-help groups. Additionally, those failed entrepreneurs who do not wish to re-emerge should nevertheless be given opportunities to distribute their insights. Such opportunities could be organized in the course of public events that focus on how and what to learn from failure. Finally, failure and the lessons learned from it should become an integral part of entrepreneurship education (González-López et al., 2019). In this way, aspiring entrepreneurs can profit from what others have learned by failing and at the same time gain a realistic picture of failure as a relevant entrepreneurial phenomenon.

\section{Limitations}

As a matter of course, our literature review is subject to some limitations. Applying a systematic review methodology acts as a double-edged sword (Wang and Chugh, 2014). On the one hand, a systematic review approach offers a replicable, scientific and transparent agenda for the collection and analysis of data (Tranfield et al., 2003). On the other hand, it introduces potential limitations that stem from the rigid conceptualization and execution of the research (Pittaway et al., 2004; Wang and Chugh, 2014).

In selecting the literature to be included, our search focused on peer-reviewed academic journals. In the light of quality standards, the restriction to literature from particular sources is a common practice, generally recommended for literature reviews (Bouncken et al., 2015; Wang and Chugh, 2014). However, one must be aware that knowledge disseminated via other outlets (e.g. unpublished papers and books) may be missed. As we include only articles written in English, another limitation is that the insights of researchers who publish in other languages are excluded. In terms of content, our deliberately narrow and clean definition of "failure" results in a relatively focused area of inquiry, which goes hand in hand with a rather small number of articles in the sample. Looking at other state-of-the-art literature reviews that focus on young topics and follow highly systematic review procedures (e.g. Kraus et al., 2018; Pret and Cogan, 2019), we observe comparable sample sizes. Referring to the definitional demarcation, we are aware that there exist related research areas that might hold potential for a systematic review-for instance, entrepreneurial learning from successful exit and intrapreneurial learning from project failure. For the present endeavor, we decided against extending the scope of research to include these related fields for two reasons. First, despite their relevance, positive entrepreneurial exit and project failure represent significantly different contexts (e.g. Wennberg and DeTienne, 2014 for the former and Shepherd and Kuratko, 2009 for the latter). Second, an adequate elaboration of the contextual differences would far exceed the scope of a review paper. However, we are convinced that these related topics represent fruitful areas for future research. The present paper, with its systematic, theory-informed review approach, may act as a guide for these future research endeavors. Moreover, it might be interesting, subsequently, to compare findings from different learning contexts.

Pertaining to the analysis and systematization of the data, we are aware of potential biases stemming from subjectivity (Bouncken et al., 2015). To target this shortcoming, two researchers analyzed the data separately and discussed any differences of perception. Regarding the systematization and presentation of the literature, we find our theory-based approach, which utilizes Kolb's experiential learning stages to map existing research, to be adequate and beneficial. In this approach, we apply a well-reputed framework grounded in experiential learning theory (Politis, 2005). While experiential learning theory is the most influential theoretical framework in the field of entrepreneurial learning (Fust et al., 2018), we are aware that there are other theoretical lenses that could be applied (see Wang and Chugh, 2014 for an overview). Alternatively, it would be possible for a review to utilize a purely 
processual perspective (see, e.g. Morris et al., 2012) or to map existing research into streams/ interest groups (see, e.g. Nogueira, 2019).

\section{Conclusion}

In this systematic literature review, we identify and critically evaluate the literature on entrepreneurial learning from failure. Existing research is mapped in the light of experiential learning theory. Specifically, we classify literature according to the four stages of Kolb's model of experiential learning. In this way, we provide a systematic, dynamic overview of the process of entrepreneurial learning from failure. Further, by comparing the scope of knowledge suggested by the theory with the actual knowledge available in the existing literature, we are able to detect a number of fruitful avenues for future research. Our findings reveal that the despite the infancy of the field, research already provides valuable insights regarding wide parts of the process of learning from failure. This pertains to the nature of failure and its triggering effect for learning. Moreover, a deep discussion is underway on specific factors influencing the entrepreneur's reflection on what had happened, focusing especially on the role of emotions such as grief and shame as well as the role of attribution of failure. Further, the contents of the learning that results from failure (whether of a personal, a social, an entrepreneurial or a managerial nature) and the transfer of learned content to subsequent entrepreneurial episodes receive a fair amount of attention.

Important areas that still require significant research efforts include Kolb's stages of "reflective observation" and "abstract conceptualization." With respect to the former, the role of personal attributes and behaviors such as resilience, but also ignorance and narcissism, as well as the cognitive processes underlying reflection itself still remain under-researched. With respect to the latter, the creative process of abstract conceptualization, or how entrepreneurs transform their failure-based observations into logically sound concepts, has not yet been covered. Investigating the influence of cognitive and social factors could help to better understand this process. While "active experimentation" in new entrepreneurial ventures is already widely addressed, a broader view that includes other fields of application, such as consulting and employed work, remains neglected. A more general issue that seems still unresolved pertains to the measurement of learning. In fact, learning is often self-reported and subjectively measured. While we suggest some solutions to overcome this issue, at least partly (e.g. the integration of credibility checks on how particular learnings are derived), the question of whether entrepreneurs actually learn or merely think they do still requires researchers' attention. To conclude, entrepreneurial learning from failure represents a flourishing research field that still yields a number of promising research questions. We encourage other scholars to use this article as a roadmap to examine these potentially fruitful issues.

\section{Note}

1. We are aware of earlier works, such as the conceptual article on learning from failure by Sitkin (1992) and the qualitative study on critical incidents for learning by Cope and Watts (2000). However, these articles lack the scope of the present review, as the former is contextualized within organizational learning and the latter has no explicit focus on business failure.

\section{References}

Articles of the literature review sample are marked with an asterisk $(*)$

*Amankwah-Amoah, J., Boso, N. and Antwi-Agyei, I. (2018), "The Effects of Business Failure Experience on Successive Entrepreneurial Engagements: An Evolutionary Phase Model", Group and Organization Management, Vol. 43 No. 4, pp. 648-682.

Bacon, D.R. (2016), "Reporting actual and perceived student learning in education research", Journal of Marketing Education, Vol. 38 No. 1, pp. 3-6.
Entrepreneurial learning from failure 
IJEBR

26,5

1126
Bird, B., Schjoedt, L. and Baum, J.R. (2012), "Entrepreneurs' behavior: elucidation and measurement introduction", Entrepreneurship: Theory and Practice, Vol. 36 No. 5, pp. 889-913.

*Boso, N., Adeleye, I., Donbesuur, F. and Gyensare, M. (2019), "Do entrepreneurs always benefit from business failure experience?”, Journal of Business Research, Vol. 98, pp. 370-379.

Bouncken, R.B., Gast, J., Kraus, S. and Bogers, M. (2015), "Coopetition: a systematic review, synthesis, and future research directions", Review of Managerial Science, Vol. 9 No. 3, pp. 577-601.

Bruno, A.V., Mcquarrie, E.F. and Torgrimson, C.G. (1992), "The evolution of new technology ventures over 20 years: patterns of failure, merger, and survival", Journal of Business Venturing, Vol. 7 No. 4, pp. 291-302.

*Byrne, O. and Shepherd, D.A. (2015), "Different strokes for different folks: entrepreneurial narratives of emotion, cognition, and making sense of business failure", Entrepreneurship: Theory and Practice, Vol. 39 No. 2, pp. 375-405.

Cardon, M.S., Stevens, C.E. and Potter, D.R. (2011), "Misfortunes or mistakes?: cultural sensemaking of entrepreneurial failure", Journal of Business Venturing, Vol. 26 No. 1, pp. 79-92.

Chen, J. (2013), "Selection and serial entrepreneurs", Journal of Economics and Management Strategy, Vol. 22 No. 2, pp. 281-311.

*Coad, A. (2014), "Death is not a success: reflections on business exit", International Small Business Journal, Vol. 32 No. 7, pp. 721-732.

*Cope, J. and Watts, G. (2000), "Learning by doing - an exploration of experience, critical incidents and reflection in entrepreneurial learning", International Journal of Entrepreneurial Behavior and Research, Vol. 6 No. 3, pp. 104-124.

Cope, J. (2003), "Entrepreneurial learning and critical reflection - discontinuous events as triggers for 'higher-level' learning”, Management Learning, Vol. 34 No. 4, pp. 429-450.

Cope, J. (2005), "Toward a dynamic learning perspective of entrepreneurship", Entrepreneurship: Theory and Practice, Vol. 29 No. 4, pp. 373-397.

*Cope, J. (2011), "Entrepreneurial learning from failure: an interpretative phenomenological analysis", Journal of Business Venturing, Vol. 26 No. 6, pp. 604-623.

*Corner, P.D., Singh, S. and Pavlovich, K. (2017), "Entrepreneurial resilience and venture failure", International Small Business Journal-Researching Entrepreneurship, Vol. 35 No. 6, pp. 687-708.

DeTienne, D. and Wennberg, K. (2016), "Studying exit from entrepreneurship: new directions and insights", International Small Business Journal, Vol. 34 No. 2, pp. 151-156.

Dewey, J. (1910), How We Think, D.C. Heath, New York.

Dewey, J. (1933), How We Think: A Restatement of the Relation of Reflective Thinking to the Educative Process, D.C. Heath, New York.

*Dias, A. and Teixeira, A. (2017), "The anatomy of business failure: a qualitative account of its implications for future business success", European Journal of Management and Business Economics, Vol. 26 No. 1, pp. 2-20.

Duley, J.S. (1981), "Field experience education", in Chickering, A.W. (Ed.), The Modern American College, Jossey-Bass, San Francisco.

*Eggers, J.P. and Song, L. (2015), "Dealing with failure: serial entrepreneurs and the costs of changing industries between ventures", Academy of Management Journal, Vol. 58 No. 6, pp. 1785-1803.

*Espinoza-Benavides, J. and Díaz, D. (2019), "The entrepreneurial profile after failure”, International Journal of Entrepreneurial Behavior and Research, Vol. 25 No. 8, pp. 1634-1651.

Fiol, C.M. and Lyles, M.A. (1985), "Organizational learning”, Academy of Management Review, Vol. 10 No. 4, pp. 803-813.

Flick, U. (2018), An Introduction to Qualitative Research, Sage, Los Angeles, London, New Delhi, Singapore, Washington DC, Melbourne. 
Fotopoulos, G. and Louri, H. (2000), "Location and survival of new entry", Small Business Economics, Vol. 14 No. 4, pp. 311-321.

*Frota Vasconcellos Dias, T.R. and Martens, C.D.P. (2019), "Business failure and the dimension of entrepreneurial learning: study with entrepreneurs of micro and small-sized enterprises", Brazilian Journal of Management/Revista de Administração da UFSM, Vol. 12 No. 1, pp. 107-124.

Entrepreneurial learning from failure

Fust, A.P., Jenert, T. and Winkler, C. (2018), "Experiential or self-regulated learning: a critical reflection of entrepreneurial learning processes", Entrepreneurship Research Journal, Vol. 8 No. 2, pp. 1-11.

Gibb, A.A. (1997), "Small firms' training and competitiveness. Building upon the small business as a learning organisation”, International Small Business Journal, Vol. 15 No. 3, pp. 13-29.

Gimeno, J., Folta, T.B., Cooper, A.C. and Woo, C.Y. (1997), "Survival of the fittest? Entrepreneurial human capital and the persistence of underperforming firms", Administrative Science Quarterly, Vol. 42 No. 4, pp. 750-783.

González-López, M.J., Pérez-López, M.C. and Rodríguez-Ariza, L. (2019), "Clearing the hurdles in the entrepreneurial race: the role of resilience in entrepreneurship education", Academy of Management Learning and Education, Vol. 18 No. 3, pp. 457-483.

Harrison, R.T. and Leitch, C.M. (2005), "Entrepreneurial learning: researching the interface between learning and the entrepreneurial context", Entrepreneurship: Theory and Practice, Vol. 29 No. 4, pp. 351-371.

*He, V.F., Siren, C., Singh, S., Solomon, G. and Von Krogh, G. (2018), "Keep calm and carry on: emotion regulation in entrepreneurs' learning from failure", Entrepreneurship: Theory and Practice, Vol. 42 No. 4, pp. 605-630.

Hegel, G.F. (1953), "Philosophy of right and law 1820", in Friedrich, C. (Ed.), The Philosophy of Hegel, Modern Library, New York.

*Heinze, I. (2013), "Entrepreneur sense-making of business failure”, Small Enterprise Research, Vol. 20 No. 1, pp. 21-39.

Holcomb, T.R., Ireland, R.D., Holmes, R.M. and Hitt, M.A. (2009), "Architecture of entrepreneurial learning: exploring the link among heuristics, knowledge, and action", Entrepreneurship: Theory and Practice, Vol. 33 No. 1, pp. 167-192.

Holland, J., Thomson, R. and Henderson, S. (2006), "Qualitative longitudinal research: a discussion paper, London South Bank University London.

*Huovinen, J. and Tihula, S. (2008), "Entrepreneurial learning in the context of portfolio entrepreneurship", International Journal of Entrepreneurial Behavior and Research, Vol. 14 No. 3, pp. 152-171.

*Jenkins, A. and McKelvie, A. (2016), "What is entrepreneurial failure? Implications for future research”, International Small Business Journal, Vol. 34 No. 2, pp. 176-188.

Josefy, M.A., Harrison, J.S., Sirmon, D.G. and Carnes, C. (2017), "Living and dying. Synthesizing the literature on firm survival and failure across stages of development", The Academy of Management Annals, Vol. 11 No. 2, pp. 770-799.

Kim, D.H. (1993), “The link between individual and organizational learning”, Sloan Management Review, Fall, Vol. 35, pp. 37-50.

Kolb, D. and Kolb, A.Y. (2018), "Eight important things to know about the experiential learning cycle", Australian Educational Leader, Vol. 40 No. 3, pp. 8-14.

Kolb, D. (1984), Experiential Learning. Experience as the Source of Learning and Development, Prentice Hall, Englewood Cliffs.

Kraus, S., Palmer, C., Kailer, N., Kallinger, F.L. and Spitzer, J. (2018), "Digital entrepreneurship: a research agenda on new business models for the twenty-first century", International Journal of Entrepreneurial Behavior and Research, Vol. 25 No. 2, pp. 353-375. 
IJEBR

26,5

*Lafuente, E., Vaillant, Y., Vendrell-Herrero, F. and Gomes, E. (2019), "Bouncing back from failure: entrepreneurial resilience and the internationalisation of subsequent ventures created by serial entrepreneurs", Applied Psychology, Vol. 68 No. 4, pp. 658-694.

Lewin, K. (1951), Field Theory in Social Sciences, Harper \& Row, New York.

*Lin, S., Yamakawa, Y. and Li, J. (2019), "Emergent learning and change in strategy: empirical study of Chinese serial entrepreneurs with failure experience", The International Entrepreneurship and Management Journal, Vol. 15 No. 3, pp. 773-792.

Lindh, I. and Thorgren, S. (2016), "Critical event recognition: an extended view of reflective learning”, Management Learning, Vol. 47 No. 5, pp. 525-542.

*Liu, Y., Li, Y., Hao, X. and Zhang, Y. (2019), "Narcissism and learning from entrepreneurial failure", Journal of Business Venturing, Vol. 34 No. 3, pp. 496-512.

*Mantere, S., Aula, P., Schildt, H. and Vaara, E. (2013), "Narrative attributions of entrepreneurial failure", Journal of Business Venturing, Vol. 28 No. 4, pp. 459-473.

McGrath, R.G. (1999), "Falling forward: real options reasoning and entrepreneurial failure", Academy of Management Review, Vol. 24 No. 1, pp. 13-30.

McLeod, J. (2003), "Why we interview now-reflexivity and perspective in a longitudinal study", International Journal of Social Research Methodology, Vol. 6 No. 3, pp. 201-211.

Mezirow, J. (1991), Transformative Dimensions of Adult Learning, Jossey-Bass, San Francisco.

Minniti, M. and Bygrave, W. (2001), "A dynamic model of entrepreneurial learning”, Entrepreneurship: Theory and Practice, Vol. 25 No. 3, pp. 5-16.

Mitchell, W. and Singh, K. (1993), "Death of the lethargic: effects of expansion into new technical subfields on performance in a firm's base business", Organization Science, Vol. 4 No. 2, pp. 152-180.

Morris, M.H., Kuratko, D.F., Schindehutte, M. and Spivack, A.J. (2012), "Framing the entrepreneurial experience", Entrepreneurship: Theory and Practice, Vol. 36 No. 1, pp. 11-40.

*Mueller, B.A. and Shepherd, D.A. (2016), "Making the most of failure experiences: exploring the relationship between business failure and the identification of business opportunities", Entrepreneurship: Theory and Practice, Vol. 40 No. 3, pp. 457-487.

Nahata, R. (2019), "Success is good but failure is not so bad either: serial entrepreneurs and venture capital contracting", Journal of Corporate Finance, Vol. 58, pp. 624-649.

Nason, R.S., McKelvie, A. and Lumpkin, G.T. (2015), "The role of organizational size in the heterogeneous nature of corporate entrepreneurship", Small Business Economics, Vol. 45 No. 2, pp. 279-304.

*Nielsen, K. and Sarasvathy, S.D. (2016), “A market for lemons in serial entrepreneurship? Exploring type I and type II errors in the restart decision", Academy of Management Discoveries, Vol. 2 No. 3, pp. 247-271.

Nogueira, T.F. (2019), “Entrepreneurial learning: what do we mean by it?”, The Learning Organization, Vol. 26 No. 6, pp. 560-573.

*Paik, Y. (2014), "Serial entrepreneurs and venture survival: evidence from US venture-capitalfinanced semiconductor firms", Strategic Entrepreneurship Journal, Vol. 8 No. 3, pp. 254-268.

Parker, S.C. (2013), "Do serial entrepreneurs run successively better-performing businesses?”, Journal of Business Venturing, Vol. 28 No. 5, pp. 652-666.

Perkins, S.E. (2014), "When does prior experience pay? Institutional experience and the multinational corporation”, Administrative Science Quarterly, Vol. 59 No. 1, pp. 145-181.

Piaget, J. (1971), Psychology and Epistemology, Penguin Books, Middlesex.

*Pittaway, L. and Thorpe, R. (2012), "A framework for entrepreneurial learning: a tribute to Jason Cope”, Entrepreneurship and Regional Development, Vol. 24 Nos 9/10, pp. 837-859. 
Pittaway, L., Robertson, M., Munir, K., Denyer, D. and Neely, A. (2004), "Networking and innovation: a systematic review of the evidence", International Journal of Management Reviews, Vols 5-6 Nos 3/4, pp. 137-168.

Podsakoff, P.M. and Organ, D.W. (1986), "Self-reports in organizational research: problems and prospects", Journal of Management, Vol. 12 No. 4, pp. 531-544.

Entrepreneurial learning from failure

*Politis, D. and Gabrielsson, J. (2009), "Entrepreneurs' attitudes towards failure: an experiential learning approach”, International Journal of Entrepreneurial Behavior and Research, Vol. 15 No. 4, pp. 364-383.

*Politis, D. (2005), "The process of entrepreneurial learning: a conceptual framework", Entrepreneurship: Theory and Practice, Vol. 29 No. 4, pp. 399-424.

Politis, D. (2008), “Does prior start-up experience matter for entrepreneurs' learning?”, Journal of Small Business and Enterprise Development, Vol. 15 No. 3, pp. 472-489.

Pret, T. and Cogan, A. (2019), "Artisan entrepreneurship: a systematic literature review and research agenda", International Journal of Entrepreneurial Behavior and Research, Vol. 25 No. 4, pp. 592-614.

*Pretorius, M. and Le Roux, I. (2011), "Successive failure, repeat entrepreneurship and no learning: a case stud: original research", SA Journal of Human Resource Management, Vol. 9 No. 1, pp. 1-13.

Ravasi, D. and Turati, C. (2005), "Exploring entrepreneurial learning: a comparative study of technology development projects", Journal of Business Venturing, Vol. 20 No. 1, pp. 137-164.

*Rerup, C. (2005), "Learning from past experience: footnotes on mindfulness and habitual entrepreneurship", Scandinavian Journal of Management, Vol. 21 No. 4, pp. 451-472.

Sarasvathy, S.D. (2001), "Causation and effectuation: toward a theoretical shift from economic inevitability to entrepreneurial contingency", Academy of Management Review, Vol. 26 No. 2, pp. 243-263.

Schwandt, D.R. (2005), "When managers become philosophers: integrating learning with sensemaking", Academy of Management Learning and Education, Vol. 4 No. 2, pp. 176-192.

*Shepherd, D.A. and Kuratko, D.F. (2009), "The death of an innovative project: how grief recovery enhances learning”, Business Horizons, Vol. 52 No. 5, pp. 451-458.

*Shepherd, D.A., Wiklund, J. and Haynie, J.M. (2009), "Moving forward: balancing the financial and emotional costs of business failure", Journal of Business Venturing, Vol. 24 No. 2, pp. 134-148.

*Shepherd, D.A. (2003), "Learning from business failure: propositions of grief recovery for the selfemployed", Academy of Management Review, Vol. 28 No. 2, pp. 318-328.

Short, J. (2009), “The art of writing a review article”, Journal of Management, Vol. 35 No. 6, pp. 1312-1317.

*Singh, S., Corner, P.D. and Pavlovich, K. (2007), "Coping with entrepreneurial failure", Journal of Management and Organization, Vol. 13 No. 4, pp. 331-344.

*Singh, S., Corner, P.D. and Pavlovich, K. (2015), "Failed, not finished: a narrative approach to understanding venture failure stigmatization", Journal of Business Venturing, Vol. 30 No. 1, pp. 150-166.

Sitkin, S.B. (1992), "Learning through failure - the strategy of small losses", Research in Organizational Behavior, Vol. 14 No. 1, pp. 231-266.

*Stam, E., Audretsch, D. and Meijaard, J. (2008), "Renascent entrepreneurship", Journal of Evolutionary Economics, Vol. 18 Nos 3-4, pp. 493-507.

Tranfield, D.R., Denyer, D. and Smart, P. (2003), "Towards a methodology for developing evidenceinformed management knowledge by means of systematic review", British Journal of Management, Vol. 14 No. 3, pp. 207-222.

*Ucbasaran, D., Westhead, P., Wright, M. and Flores, M. (2010), "The nature of entrepreneurial experience, business failure and comparative optimism", Journal of Business Venturing, Vol. 25 No. 6, pp. 541-555.

*Ucbasaran, D., Westhead, P. and Wright, M. (2011), "Why serial entrepreneurs don't learn from failure", Harvard Business Review, Vol. 89 No. 4, p. 26. 
IJEBR

26,5

1130
*Ucbasaran, D., Shepherd, D.A., Lockett, A. and Lyon, S.J. (2013), "Life after business failure: the process and consequences of business failure for entrepreneurs", Journal of Management, Vol. 39 No. 1, pp. 163-202.

*Walsh, G. and Cunningham, J. (2017), "Regenerative failure and attribution: examining the underlying processes affecting entrepreneurial learning", International Journal of Entrepreneurial Behavior and Research, Vol. 23 No. 4, pp. 688-707.

Wang, C.L. and Chugh, H. (2014), "Entrepreneurial learning: past research and future challenges", International Journal of Management Reviews, Vol. 16 No. 1, pp. 24-61.

Wdowiak, M.A., Schwarz, E.J. and Parastuty, Z. (2017), "How to teach about entrepreneurial failure? Objectives, assumptions, and evidence", paper presented at the ECSB Entrepreneurship Education Conference (3E), 10 May-12 May, Cork.

*Wei, J., Chen, Y., Zhang, J. and Gong, Y. (2019), "Research on factors affecting the entrepreneurial learning from failure: an interpretive structure model", Frontiers in Psychology, Vol. 10, Art. 1304, pp. 1-10.

Wennberg, K. and DeTienne, D.R. (2014), “What do we really mean when we talk about 'exit?' A critical review of research on entrepreneurial exit", International Small Business Journal, Vol. 32 No. 1, pp. 4-16.

Wennberg, K., Wiklund, J., DeTienne, D.R. and Cardon, M.S. (2010), "Reconceptualizing entrepreneurial exit: divergent exit routes and their drivers", Journal of Business Venturing, Vol. 25 No. 4, pp. 361-375.

*Yamakawa, Y. and Cardon, M.S. (2015), "Causal ascriptions and perceived learning from entrepreneurial failure”, Small Business Economics, Vol. 44 No. 4, pp. 797-820.

*Yamakawa, Y., Peng, M.W. and Deeds, D.L. (2015), "Rising from the ashes: cognitive determinants of venture growth after entrepreneurial failure", Entrepreneurship: Theory and Practice, Vol. 39 No. 2, pp. 209-236.

\section{Appendix}

Reasons for exclusion of articles from the final sample

Guideline for exclusion: To be included in our final sample, an article (1) had to be settled within the context of entrepreneurship, (2) had to target the context of failure (defined as the closure of a business because it has not met a minimum threshold for economic viability) and (3) had to provide insights that contribute to a better understanding of learning

Papers that did not meet one or more of these criteria were excluded from the sample

\begin{tabular}{|c|c|c|}
\hline Exclusion criterion & Ratio behind exclusion & Examples \\
\hline $\begin{array}{l}\text { (1) Lack of } \\
\text { entrepreneurial } \\
\text { focus }\end{array}$ & $\begin{array}{l}\text { As we wish to contribute to the discipline } \\
\text { of entrepreneurship, a clean differentiation } \\
\text { from knowledge targeting other possible } \\
\text { settings and disciplines is necessary }\end{array}$ & $\begin{array}{l}\text { (1) Studies on organizational learning } \\
\text { (2) Studies that are limited to a } \\
\text { macroeconomic perspective }\end{array}$ \\
\hline $\begin{array}{l}\text { (2) Absence of } \\
\text { failure (as } \\
\text { defined) }\end{array}$ & $\begin{array}{l}\text { We paid particular attention to a clean } \\
\text { definition of failure (see above). } \\
\text { Consequently, studies that clearly utilized } \\
\text { a different understanding of failure, were } \\
\text { excluded }\end{array}$ & $\begin{array}{l}\text { (1) Studies that perceive failure in the } \\
\text { sense of "setback" (i.e. a non- } \\
\text { discontinuous event) } \\
\text { (2) Studies that only deal with the fear of } \\
\text { failure }\end{array}$ \\
\hline $\begin{array}{l}\text { (3) Lack of focus on } \\
\text { learning }\end{array}$ & $\begin{array}{l}\text { To contribute to the understanding of } \\
\text { learning, a study had to be at least clearly } \\
\text { linked their findings to the phenomenon of } \\
\text { learning (e.g. discussing the relationship of } \\
\text { emotions and learning) }\end{array}$ & $\begin{array}{l}\text { (1) Studies on antecedents to failure } \\
\text { (2) Studies on effects of failure without } \\
\text { targeting learning or at least } \\
\text { providing links to learning }\end{array}$ \\
\hline
\end{tabular}

Table A1.

Reasons for exclusion of articles 
Methods

\begin{tabular}{|c|c|c|c|c|c|c|}
\hline \multirow[b]{2}{*}{ Approach } & \multirow[b]{2}{*}{ Number of publications } & \multicolumn{4}{|c|}{ Sample } & \multirow{3}{*}{1131} \\
\hline & & Minimum & Mean & Median & Maximum & \\
\hline Conceptual & 8 & & & & & \\
\hline Qualitative & 14 & 1 & 10 & 7 & 30 & \\
\hline Quantitative & 16 & 142 & 455 & 240 & 2,024 & $\begin{array}{l}\text { 1able A } \\
\text { Methodologies }\end{array}$ \\
\hline Multi-method & 2 & 114 & 247 & 247 & 380 & $\begin{array}{r}\text { studies on } \\
\text { stures }\end{array}$ \\
\hline
\end{tabular}

\section{Corresponding author}

Wolfgang Lattacher can be contacted at: wolfgang.lattacher@aau.at 